THE NET EFFECT OF ADVICE ON STRATEGY-PROOF MECHANISMS:

AN EXPERIMENT FOR THE VICKREY AUCTION

\author{
Takehito Masuda \\ Ryo Mikami \\ Toyotaka Sakai \\ Shigehiro Serizawa \\ Takuma Wakayama
}

December 2020

The Institute of Social and Economic Research

Osaka University

6-1 Mihogaoka, Ibaraki, Osaka 567-0047, Japan 


\title{
The net effect of advice on strategy-proof mechanisms: An experiment for the Vickrey auction*
}

\author{
Takehito Masuda $^{\dagger} \quad$ Ryo Mikami ${ }^{\ddagger} \quad$ Toyotaka Sakai $^{\S}$ \\ Shigehiro Serizawa Takuma Wakayamall
}

December 3, 2020

\begin{abstract}
We conducted laboratory experiments for the multi-unit Vickrey auction with and without advice to subjects on strategy-proofness. The rate of truth-telling among the subjects without advice was $20 \%$, whereas the rate increased to $47 \%$ among those who received advice. By conducting similar experiments for the pay-your-bid auction, which is not strategy-proof, we confirm that the increase in truth-telling owes significantly to the net advice effect, i.e., the effect beyond the so-called experimenter demand effect. Moreover, providing advice improves efficiency in the Vickrey auction, particularly in the early periods, when subjects are less experienced. It is well known that subjects tend to overbid in Vickrey auction experiments. Our results indicate the possibility that providing a piece of simple advice decreases such overbidding by promoting a better understanding of the strategy-proofness property in the Vickrey auction. Strategy-proof mechanisms are sometimes criticized because players often fail to find the benefit in telling the truth; however, our observations show that introducing advice on the property of strategy-proofness helps them behave "correctly."
\end{abstract}

Keywords: advice effect; strategy-proofness; Vickrey auction; pay-your-bid auction; market design

JEL codes: D44; D71; D61; D82

*A version of this paper was previously circulated under the title "A strategy-proof mechanism should be announced strategy-proof: An experiment for the Vickrey auction." We are grateful to John Duffy, the editor of this journal, and two anonymous referees for their useful comments and suggestions that improved the paper. We thank Yoshitaka Okano for providing the z-Tree program of the Ausubel auction and very helpful discussion. We also thank Pablo Guillen, Nobuyuki Hanaki, Naoko Nishimura, Hans-Theo Normann, Alvin Roth, Tayfun Sönmez, Utku Ünver, Takashi Yamagata, and Lianming Zhu for their helpful comments. Yuki Hamada provided excellent research assistance. We gratefully acknowledge financial support from the Joint Usage/Research Center at ISER, Osaka University; Osaka University's International Joint Research Promotion Program (Type A); and Grant-in-aid for Research Activity, Japan Society for the Promotion of Science (15H05728, 20H05631, 20KK0027).

${ }^{\dagger}$ Faculty of Economics and Law, Shinshu University. E-mail: tmasuda@shinshu-u.ac.jp

${ }^{\ddagger}$ Graduate School of Economics, Osaka University. E-mail: ryomyself@gmail.com

$\S$ Department of Economics, Keio University. E-mail: tsakai@z5.keio.jp

IISER, Osaka University. E-mail: serizawa@iser.osaka-u.ac.jp

${ }^{\|}$Faculty of Economics, Ryukoku University. E-mail: wakayama@econ.ryukoku.ac.jp 


\section{Introduction}

The technology for the design of economic mechanisms has grown rapidly in the last few decades. Practical applications of economic mechanisms now include spectrum auctions (Milgrom (2000)), school choice (Abdulkadiroğlu and Sönmez (2003)), and kidney exchange (Roth et al. (2004)), among many others. A preferred property of such mechanisms is strategy-proofness, which ensures that truthfully reporting their own type is always a dominant strategy for every participant. As long as a strategyproof mechanism is employed, everyone has an incentive to report his/her true type, so that the social goal is realized through the collection of accurate information.

However, it has often been observed in laboratory experiments involving strategyproof mechanisms that telling the truth is far from universal (e.g., Attiyeh et al. (2000), Kawagoe and Mori (2001), Cason et al. (2006), and Chen and Sönmez (2006)). ${ }^{1}$ These observations have been considered an anomaly to the theory, encouraging skepticism of the practical performance of strategy-proof mechanisms. A prominent example is the Vickrey auction (Vickrey (1961)), under which many experimental studies have observed overbidding. ${ }^{2}$ However, this does not imply that the strategy-proofness of the Vickrey auction is useless in reality. Simply, it suggests the necessity of developing some device that puts strategy-proofness to work, making the Vickrey auction useful in real-life applications.

It is not easy for an average person to realize that the Vickrey auction is strategyproof. $^{3}$ That is, the Vickrey auction does not exhibit the expected performance only by explaining the auction rule to participants. A simple idea to resolve this issue is to announce the strategy-proofness of the Vickrey auction to users, which is what we shall attempt in this experimental research.

In our experiment, we provide advice on the strategy-proofness of the Vickrey

\footnotetext{
${ }^{1}$ Velez and Brown (2020) study the phenomenon of strategy-proof mechanism experiments from a different angle. They identify the condition under which the untruthful behavior is "empirically" plausible.

${ }^{2}$ Several experimental studies report that most subjects do not reveal their true type in the Vickrey auction even in the single-unit case. Kagel and Levin (1993) find that the rate of sincere bidding is approximately $27 \%$ of all bids. Garratt et al. (2012) report that even though the subjects are familiar with bidding in eBay auctions, approximately four out of five subjects failed to bid sincerely. Manelli et al. (2006) and Kagel and Levin (2009) observe that subjects in a Vickrey auction experiment tend to overbid, compared with subjects in the Ausubel auction (Ausubel (2004)), which is a dynamic counterpart of the Vickrey auction. See Kagel and Levin (2016) for a survey on the experimental results of the Vickrey auction.

${ }^{3}$ Hassidim et al. (2017) provide possible explanations as to why individuals do not report their true preferences under the deferred acceptance mechanism, which is a well-known strategy-proof mechanism in the context of two-sided matching - both in the field and in the lab. They cite "failure to identify the dominant strategy" as one of the explanations.
} 
auction to the subjects, and examine its effect on subjects' behaviors and the efficiency of outcomes. Our experiment deals with a case where multiple units of an item are to be sold under the Vickrey auction. We observe that although the rate of sincere bidding is approximately $20 \%$ without advice, it increases to $46.9 \%$ once subjects are advised as to the strategy-proofness of the Vickrey auction.

One might suspect that this increase stems from a so-called experimenter demand effect (Zizzo (2009)). Thus, we attempt to detect whether an effect of advice exists beyond the experimenter demand effect, which we call the net advice effect. In doing this, we conduct similar experiments for the pay-your-bid auction, which is not strategy-proof. ${ }^{4}$ We used the same advice across auction mechanisms to cause similar experimenter demand effects in both auctions. ${ }^{5}$ The comparison with the pay-your-bid auction reveals that the Vickrey auction has a large net advice effect. Moreover, for the Vickrey auction, the effect of the advice is stronger for subjects with a perfect score in a quiz on the auction rules than for other subjects. ${ }^{6}$

In the literature on auction theory, overbidding in the Vickrey/second price auction has been attributed to the joy of winning (Cooper and Fang (2008)), a cognitive limit on contingent reasoning ( $\mathrm{Li}(2017)$ ), the underestimation of possible losses (Georganas et al. (2017)), and so on. Our results, however, show the possibility that merely providing a piece of simple advice decreases overbidding by promoting a better understanding of the strategy-proofness property in the Vickrey auction. Our experimental results suggest that before operating strategy-proof mechanisms, explaining the property of strategy-proofness helps those who are unaware of its property to behave "correctly."

Related literature. The effect of providing advice on strategy-proof mechanisms has recently been studied by several authors (Guillen and Hing (2014); Ding and Schotter $(2017 b))$. These studies use two-sided matching models to test whether providing advice will affect the rate of truth-telling. A closely related work by Guillen and Hakimov (2018) finds that announcing the strategy-proofness of strategy-proof matching mechanisms increases the rate of truth-telling, while providing a detailed explanation

\footnotetext{
${ }^{4}$ The pay-your-bid auction is used by many countries in practical Treasury bond allocations. See Brenner et al. (2009) and Marszalec (2017) for more details.

${ }^{5}$ To avoid deception, we added a careful notice to the advice. See Section Section 2.2 for more details.

${ }^{6}$ Guillen and Hakimov (2017) analyze the effect of the quiz score on the rate of truth-telling in a strategy-proof matching mechanism experiment. Similarly, Hanaki et al. (2016) find that subjects with higher cognitive skill are more likely to perform one step of elimination of dominated strategy.
} 
of the mechanism has the opposite effect. ${ }^{7}$ These results suggest that advice helps participants confirm individual optimality of truth-telling. To the best of our knowledge, our study is the first one that tests the role of advice in the literature of auction studies. $^{8}$

To enhance how individuals understand incentive properties, Saijo et al. (2007) and Li (2017) attempt to strengthen strategy-proofness. Saijo et al. (2007) emphasize that, even if a mechanism is strategy-proof, it often admits the presence of an inefficient Nash equilibrium composed of mis-reporting. Saijo et al. (2007) strengthen strategy-proofness to "secure implementability" by additionally requiring that no Nash equilibrium realizes an outcome that is not the "true" outcome. An experimental study by Cason et al. (2006) compares bidding behavior under a securely implementable (and so strategy-proof) mechanism and that of other strategy-proof mechanisms. They observe that the rate of truth-telling in the former is higher than that in the latter.

Li (2017) proposes a stronger version of strategy-proofness called "obvious strategyproofness" that can be applied to dynamic mechanisms such as ascending auctions or matching algorithms. In a problem where a single item is auctioned, the ascending auction is obviously strategy-proof, but the Vickrey auction is not. In an experiment where a single item is auctioned, Li observes that the ratio of dominant strategies played by subjects is significantly higher under the ascending clock auction than under the Vickrey auction.

However, given that the class of strategy-proof mechanisms is already narrow (e.g., Holmström (1979)), strengthening strategy-proofness severely restricts the admissible class of mechanisms. On the other hand, our approach of providing advice can be applied to any strategy-proof mechanism in any environment. The Vickrey auction is neither securely implementable nor obviously strategy-proof, but giving advice drastically improves its performance on truth-telling.

\footnotetext{
${ }^{7}$ Guillen and Hakimov (2018) consider top-down advice (e.g., advice given by the mechanism administrator). Several studies examine whether the source of advice affects the truth-telling behavior: advice given to children by their parents (Ding and Schotter (2017b)); peer information sharing in networks (Ding and Schotter (2017a)); and third-party advice such as websites (Guillen and Hing (2014)).

${ }^{8}$ Shogren et al. (2001) conduct a Vickrey auction experiment under the condition that subjects are informed of the strategy-proofness of the Vickrey auction. However, they do not test the effect of the advice in that they do not conduct a Vickrey auction experiment without advice. In addition, in some experimental studies that aim to elicit real valuations for items through incentive-compatible mechanisms such as the Vickrey auction, the experimental instructions explicitly inform subjects that truth-telling is the best strategy (e.g., Grether and Plott (1979) and List (2001)). However, these studies do not test whether or not providing such information will affect the rate of truth-telling.
} 
Organization. The remainder of the paper is organized as follows. Section 2 describes the theoretical background and our experimental design. Section 3 presents our experimental results. Section 4 discusses our results and provides additional analyses. Section 5 provides concluding remarks.

\section{Experimental design}

\subsection{Theoretical considerations}

There are three bidders, $\{1,2,3\}$, and two indivisible, identical objects to be auctioned. Each bidder is admitted to demand two units. Bidder $i$ 's valuation for the objects is denoted by $v_{i}=\left(v_{i}^{1}, v_{i}^{2}\right)$ where $v_{i}^{j}$ denotes the value that bidder $i$ assigns to the $j$-th unit. Bidder $i$ 's valuation is drawn independently from the uniform distribution on $V \equiv\left\{\left(v_{i}^{1}, v_{i}^{2}\right) \in[0, \bar{v}]^{2}: v_{i}^{1} \geq v_{i}^{2}\right\}$, where $\bar{v}>0$. Given any $v_{i} \in V$, bidder $i$ 's utility of obtaining $k$ units of objects and paying $m_{i} \in \mathbb{R}$ units of money is: ${ }^{9}$

$$
U\left(k, m_{i} ; v_{i}\right) \equiv \begin{cases}v_{i}^{1}+v_{i}^{2}-m_{i} & \text { if } k=2 \\ v_{i}^{1}-m_{i} & \text { if } k=1 \\ -m_{i} & \text { if } k=0\end{cases}
$$

A list $v=\left(v_{1}, v_{2}, v_{3}\right) \in V^{3}$ is a valuation profile. An assignment function is a function $d: V^{3} \rightarrow\{0,1,2\}^{3}$ that satisfies the following resource constraint: for each $v \in V^{3}, d_{1}(v)+d_{2}(v)+d_{3}(v)=2$. A payment function is a function $m: V^{3} \rightarrow \mathbb{R}^{3}$. A rule is a pair of assignment and payment functions, $\varphi=(d, m)$. Given any $v \in V^{3}$, the projection of $\varphi(v)=(d(v), m(v))$ on $i \in\{1,2,3\}$ is denoted by $\varphi_{i}(v)=\left(d_{i}(v), m_{i}(v)\right)$, that is, $d_{i}(v) \in\{0,1,2\}$ is the number of the objects $i$ obtains, and $m_{i}(v) \in \mathbb{R}$ is the amount of money $i$ pays.

We are interested in rules in which sincere bidding is a weakly dominant strategy for everyone. Formally:

Strategy-proofness: For each $v \in V^{3}$, each $i \in\{1,2,3\}$, and each $v_{i}^{\prime} \in V, U\left(\varphi_{i}(v) ; v_{i}\right) \geq$ $U\left(\varphi_{i}\left(v_{i}^{\prime}, v_{-i}\right) ; v_{i}\right)$.

The following rules are central in the literature on auction theory.

\footnotetext{
${ }^{9}$ In standard auctions such as the Vickrey auction, the pay-your-bid auction, introduced later, $m_{i}=0$ if $k=0$.
} 
- Vickrey auction: Each bidder simultaneously submits a bid vector $b_{i}=\left(b_{i}^{1}, b_{i}^{2}\right) \in$ $V$. After the seller collects all bidders' bids, the seller ranks them from the highest to the lowest bid and allocates the two units to the two highest bids. If bidder $i$ wins one (respectively, two) unit, then the bidder has to pay the highest bids (respectively, the sum of the highest and the second-highest bids) from among the other bidders' losing bids.

- Pay-your-bid auction: Each bidder simultaneously submits a bid vector $b_{i}=$ $\left(b_{i}^{1}, b_{i}^{2}\right) \in V$. After the seller collects all bidders' bids, the seller ranks them from the highest to the lowest bid and allocates the two units to the two highest bids. If bidder $i$ wins one (respectively, two) unit, then the bidder has to pay $b_{i}^{1}$ (respectively, $b_{i}^{1}+b_{i}^{2}$ ).

The most important feature of the Vickrey auction is strategy-proofness. However, many previous experimental studies report that bidders tend to overbid in Vickrey auctions. The pay-your-bid auction is widely used in real life, while the Vickrey auction is not so. However, in contrast to the Vickrey auction, the pay-your-bid auction violates strategy-proofness.

\subsection{Experimental procedures}

We conducted an experiment to test the effect of advice for the Vickrey auction. We used between-subjects design. To distinguish between whether subjects follow the advice because they understand it or obey the advice without understanding it, we also conducted corresponding experiments for the pay-your-bid auction. We have four types of treatments in total:

1. Treatment VA: the Vickrey auction with advice

2. Treatment VN: the Vickrey auction without advice

3. Treatment PA: the pay-your-bid auction with advice

4. Treatment PN: the pay-your-bid auction without advice

In each treatment, three bidders compete for two units of an item. For each bidder, two integer valuations are drawn from the uniform distribution with the interval 0 to 1,000 with increments of 10 . Then, the larger (respectively, smaller) integer is assigned the valuation for the first (respectively, second) unit. All valuations are displayed in Japanese yen (JPY). 
Table 1: Summary of treatments.

\begin{tabular}{cccccc}
\hline Treatment & Auction rule & Advice & Date & \# of Sessions & \# of Subjects (Groups) \\
\hline VA & Vickrey & Yes & Mar-15 & 3 & $63(21)$ \\
VN & Vickrey & No & Mar-15 & 2 & $48(16)$ \\
PA & Pay-your-bid & Yes & Jul-16 & 3 & $69(23)$ \\
PN & Pay-your-bid & No & Jul-16 & 3 & $72(24)$ \\
\hline
\end{tabular}

VA, PA, and PN each had three experimental sessions, whereas VN had two sessions. We conducted these 11 sessions at Osaka University in March 2015 and July 2016. We recruited student subjects from Osaka University through campus-wide advertisements. None of the students was experienced in this particular type of experiment. No subject attended more than one session. Our experiment was computerized using the experimental software z-Tree (Fischbacher (2007)). Twenty-one or twenty-four subjects participated in each session. Table 1 summarizes the number of observations. Figure 1 illustrates the timeline of one session.

Each subject was seated at a computer terminal assigned by a lottery. All terminals were separated by partitions. No communication among subjects was allowed. Each subject had a set of printed instructions and a recording sheet. ${ }^{10}$ The experimenter read aloud the instructions. Then, subjects answered a 17-question quiz that tested whether they understood the auction rule that they had been informed of a short time ago. Every correct answer was worth $\$ 0.3(\$ 1=$ JPY 100). The experimenter read aloud the answers to the quiz. Subsequently, only in VA and PA, the experimenter distributed a paper with written advice and also read it aloud. The text of the advice is as below:

"The following advice is about the auction in which you are participating. Please consider carefully whether this advice is true or false. It is completely up to you whether you follow the advice or not.

You can maximize your earnings by bidding your valuations as they are, regardless of what others bid."

Note that the advice involves no deception problem for VA and PA. The subjects were given time to ask questions before proceeding to two practice periods and to the 25 successive payment periods under the random matching protocol. At the beginning of each period, all subjects were separated into groups of three. At the bidding stage,

\footnotetext{
${ }^{10}$ The full set of experimental instructions (including screen shots, the quiz, and the questionnaire) is provided in Online Appendix F-J and $\mathrm{O}-\mathrm{P}$.
} 


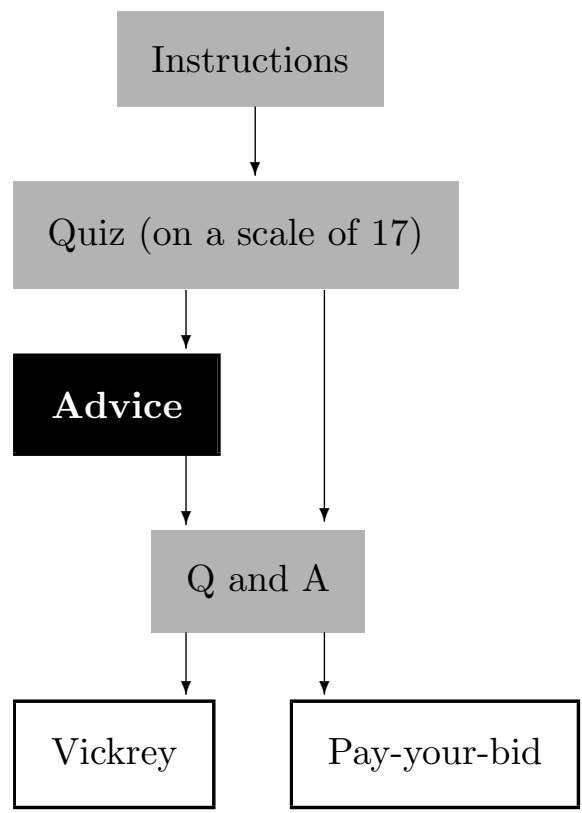

- Group of three;

- Two units;

- Twenty-five periods, random match; and

- Valuations are uniformly distributed on $\{0,10, \ldots, 1000\}$.

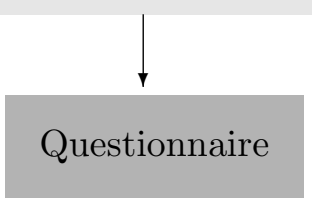

Figure 1: Timeline of one session.

each subject was asked to enter his/her two bids as nonnegative integers - such that the first unit bid is weakly greater than that of the second unit bid - into a box on the display screen. We set the maximum feasible first unit bid to 2,000.

After the 25 payment periods, the subjects completed a questionnaire and were immediately paid in cash. Each subject was privately paid the sum of his/her earnings over the 25 periods. The value of the individual payments ranged from $\$ 5.9$ to $\$ 70.3$.

\section{Experimental results}

\subsection{Level of understanding for auction rules}




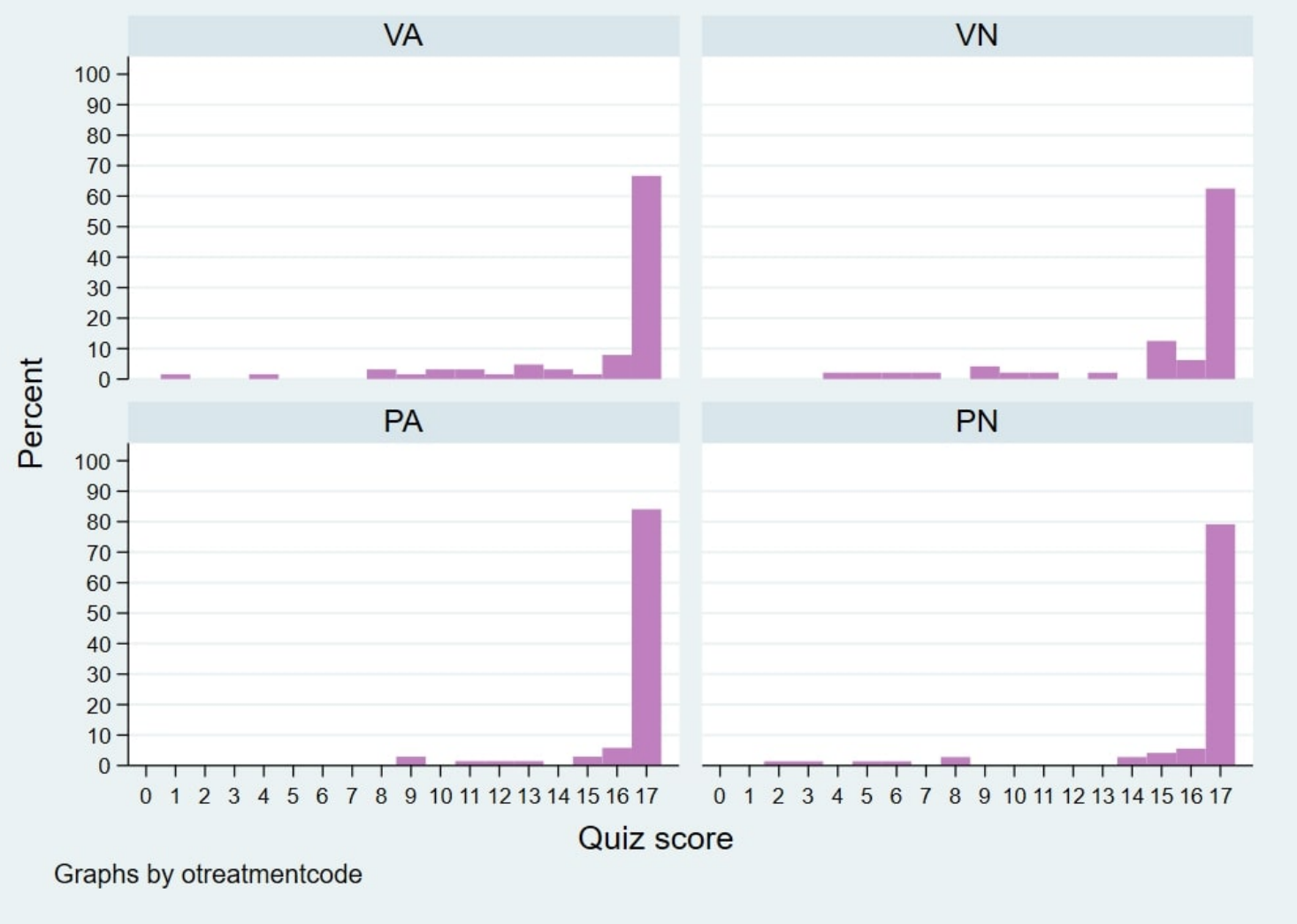

Figure 2: Distribution of quiz scores.

Figure 2 displays the distributions of quiz scores. The scores range from 0 to 17 . A first look at Figure 2 shows clear evidence that over $60 \%$ of the subjects received a perfect score in the Vickrey auction, while over $80 \%$ did so in the pay-your-bid auction. Given an auction rule, we found no statistical difference in the score distributions with and without advice. ${ }^{11}$ Similarly, we found no statistical evidence to support the different levels of understanding between the two auctions regardless of the presence of advice. ${ }^{12}$ In summary, we have the following result.

Result 1 (Level of understanding for auction rules). The majority of subjects had a thorough understanding of the auction rules prior to playing regardless of whether they participated in the Vickrey or the pay-your-bid auction.

\footnotetext{
${ }^{11} \mathrm{~A}$ two-sample Kolmogorov-Smirnov (K-S) test for the equality of two score distributions had a $p$-value $>0.90$ for both VA vs. VN and PA vs. PN. The same conclusions also hold under a chi-square test.

${ }^{12}$ The K-S test had a $p$-value $>0.10$ for all pairwise comparisons of (i) VA vs. PA, (ii) VA vs. PN, (iii) VN vs. PA, and (iv) VN vs. PN.
} 


\subsection{Bidding behavior}

For a given unit, we say that a bid is sincere if it matches exactly the valuation drawn for the unit. Similarly, we say that a bid is over (respectively, under) if the bid is more (respectively, less) than the valuation. For example, if valuations and bids are $v_{1}=(800,300), v_{2}=(600,400), v_{3}=(900,500), b_{1}=(850,240), b_{2}=(600,400)$, and $b_{3}=(900,0)$, then the sincere bids are the first and second units of bidder 2 and the first unit of bidder 3. The unique overbid is bidder 1's first unit, while the remaining two bids are underbids. Hence, the overall average sincere bid rate is 0.5 (i.e., we divide the number of sincere bids by the total number of bids by the three bidders), whereas the average sincere bid rate of bidder 1,2 , and 3 is 0,1 , and 0.5 , respectively.

Figure 3 shows the scatter plots for valuations and bids in each treatment. Initially, the Vickrey treatments graphs suggest that, for unit 1, bidders with higher valuations more likely to overbid. When valuations are close to the maximum, 1,000, bids jump as high as 2,000. For unit 2, bidding behavior is polarized with an increase in underbidding: overbidding is prevalent regardless of the realized valuations. At the same time, we also observe a cluster of zero bidding when the valuation for unit 2 are no more than 500. Table 2 summarizes the classification of bids into three categories by treatments and periods. ${ }^{13}$

As Panel (a) of Table 2 (VA-VN column) shows, sincere bidding increased by $26.3 \%$ with the statement of strategy-proofness in the Vickrey auction. In particular, we observed from Panels (b) and (c) of Table 2 that the rate of sincere bidding increased more in the former 13 periods than in the latter 12 periods. Specifically, the rate of sincere bidding increased by $28.2 \%$ in the former 13 periods, while the rate increased by $24.3 \%$ in the latter 12 periods. Notice that overbidding is prevalent in the Vickrey auction without advice (VN), which amounts to $63.4 \%$ of all bids. This observation is consistent with findings in experiments of the multi-unit Vickrey auction by Manelli et al. (2006), Engelmann and Grimm (2009), and Kagel and Levin (2009).

With an explicit statement on the strategy-proofness of the Vickrey auction (VA), $45.3 \%$ of the case was overbidding, that is, this means that our advice decreased overbidding by $18.1 \%$. Moreover, we found that underbidding also decreases when the advice is given. Specifically, our advice decreased underbidding by $8.3 \%$. To compare the effect of advice on overbids and underbids, we calculate the ratio of the reduction rate of overbidding to the rate of overbidding in $\mathrm{VN}$ as well as the ratio of the reduction rate of underbidding to the rate of underbidding in VN. As a result, we find that the

\footnotetext{
${ }^{13}$ See Online Appendix Q for individual bidding data.
} 


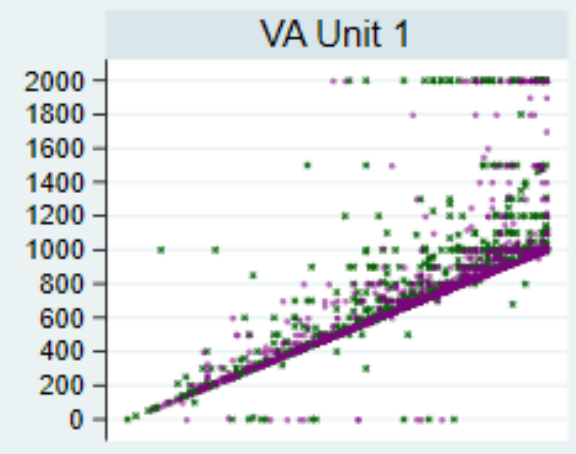

PA Unit 1

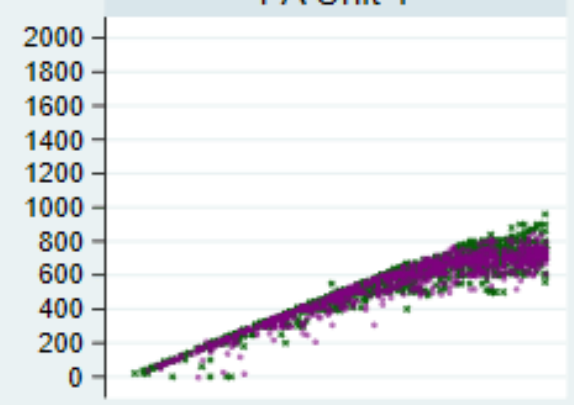

음

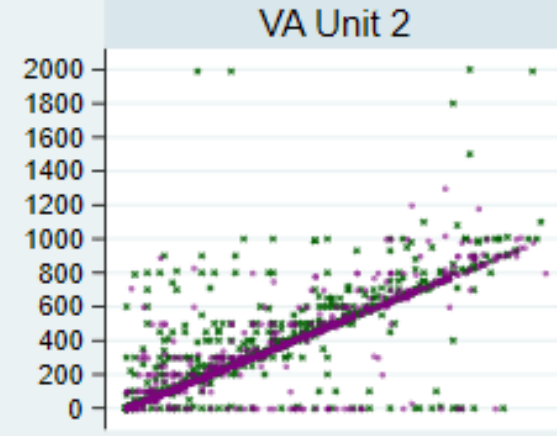

PA Unit 2

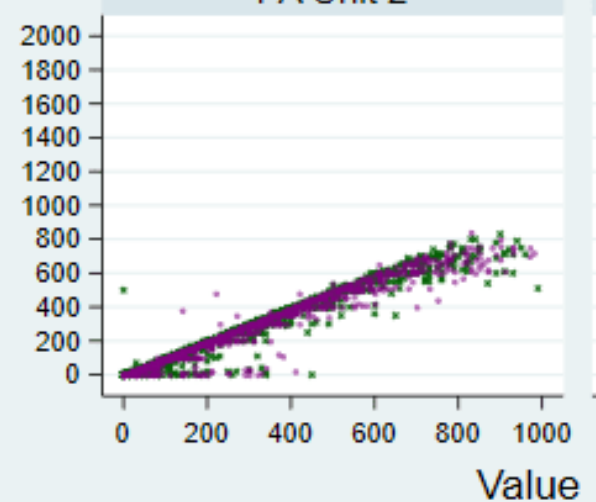

\section{* Periods 1-13 • Periods 14-25}

Graphs by unit and otreatmentcode

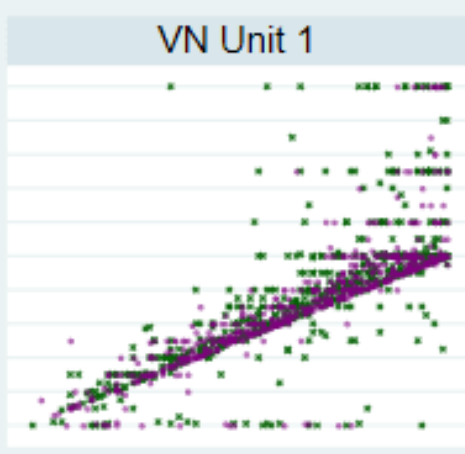

PN Unit 1

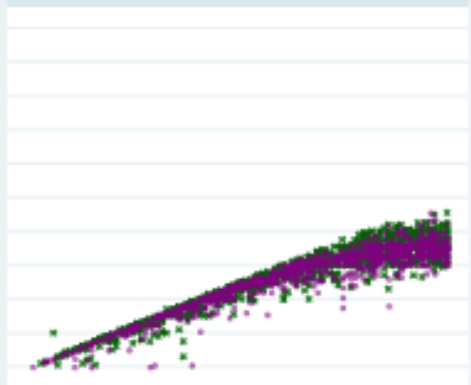

VN Unit 2

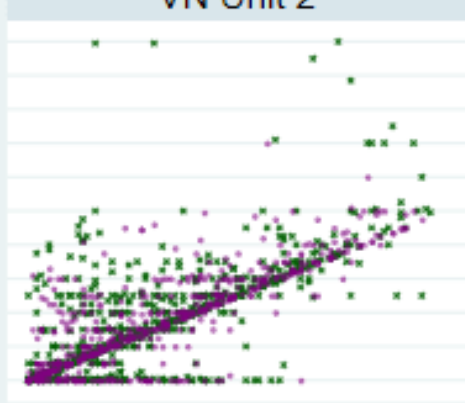

PN Unit 2

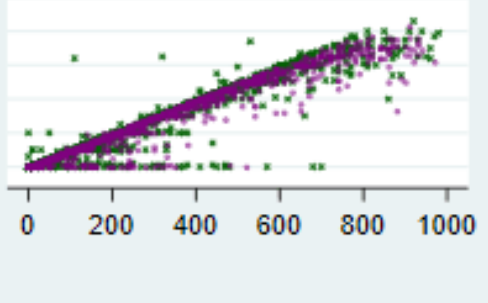

Figure 3: Scatter plots of bids. Green $\times$ and purple $\bullet$ indicate bids for the former 13 periods and latter 12 periods, respectively. 
Table 2: Bid category by treatments and periods.

(a) All

\begin{tabular}{|c|c|c|c|c|c|c|}
\hline \multirow[b]{2}{*}{ Bid category } & \multicolumn{2}{|c|}{ Vickrey } & \multirow[b]{2}{*}{$\mathrm{VA}-\mathrm{VN}$} & \multicolumn{2}{|c|}{ Pay-your-bid } & \multirow[b]{2}{*}{$P A-P N$} \\
\hline & VA & VN & & PA & PN & \\
\hline Over & $\begin{array}{c}1,427 \\
(45.30 \%)\end{array}$ & $\begin{array}{c}1,521 \\
(63.38 \%)\end{array}$ & $-18.07 \%$ & $\begin{array}{c}19 \\
(0.55 \%)\end{array}$ & $\begin{array}{c}33 \\
(0.92 \%)\end{array}$ & $-0.37 \%$ \\
\hline Sincere & $\begin{array}{c}1,478 \\
(46.92 \%)\end{array}$ & $\begin{array}{c}494 \\
(20.58 \%)\end{array}$ & $26.34 \%$ & $\begin{array}{c}287 \\
(8.32 \%)\end{array}$ & $\begin{array}{c}209 \\
(5.81 \%)\end{array}$ & $2.51 \%$ \\
\hline Under & $\begin{array}{c}245 \\
(7.78 \%)\end{array}$ & $\begin{array}{c}385 \\
(16.04 \%)\end{array}$ & $-8.26 \%$ & $\begin{array}{c}3,144 \\
(91.13 \%)\end{array}$ & $\begin{array}{c}3,358 \\
(93.28 \%)\end{array}$ & $-2.15 \%$ \\
\hline Total & 3,150 & 2,400 & & 3,450 & 3,600 & \\
\hline
\end{tabular}

(b) Periods 1-13

\begin{tabular}{|c|c|c|c|c|c|c|}
\hline \multirow[b]{2}{*}{ Bid category } & \multicolumn{2}{|c|}{ Vickrey } & \multirow[b]{2}{*}{ VA-VN } & \multicolumn{2}{|c|}{ Pay-your-bid } & \multirow[b]{2}{*}{$P A-P N$} \\
\hline & VA & VN & & PA & PN & \\
\hline Over & $\begin{array}{c}742 \\
(45.30 \%)\end{array}$ & $\begin{array}{c}785 \\
(62.90 \%)\end{array}$ & $-17.60 \%$ & $\begin{array}{c}8 \\
(0.45 \%)\end{array}$ & $\begin{array}{c}28 \\
(1.50 \%)\end{array}$ & $-1.05 \%$ \\
\hline Sincere & $\begin{array}{c}765 \\
(46.70 \%)\end{array}$ & $\begin{array}{c}231 \\
(18.51 \%)\end{array}$ & $28.19 \%$ & $\begin{array}{c}166 \\
(9.25 \%)\end{array}$ & $\begin{array}{c}109 \\
(5.82 \%)\end{array}$ & $3.43 \%$ \\
\hline Under & $\begin{array}{c}131 \\
(8.00 \%)\end{array}$ & $\begin{array}{c}232 \\
(18.59 \%)\end{array}$ & $-10.59 \%$ & $\begin{array}{c}1,620 \\
(90.30 \%)\end{array}$ & $\begin{array}{c}1,735 \\
(92.68 \%)\end{array}$ & $-2.38 \%$ \\
\hline Total & 1,638 & 1,248 & & 1,794 & 1,872 & \\
\hline
\end{tabular}

(c) Periods $14-25$

\begin{tabular}{|c|c|c|c|c|c|c|}
\hline \multirow[b]{2}{*}{ Bid category } & \multicolumn{2}{|c|}{ Vickrey } & \multirow[b]{2}{*}{$\mathrm{VA}-\mathrm{VN}$} & \multicolumn{2}{|c|}{ Pay-your-bid } & \multirow[b]{2}{*}{$P A-P N$} \\
\hline & VA & VN & & PA & PN & \\
\hline Over & $\begin{array}{c}685 \\
(45.30 \%)\end{array}$ & $\begin{array}{c}736 \\
(63.89 \%)\end{array}$ & $-18.58 \%$ & $\begin{array}{c}11 \\
(0.66 \%)\end{array}$ & $\begin{array}{c}5 \\
(0.29 \%)\end{array}$ & $0.37 \%$ \\
\hline Sincere & $\begin{array}{c}713 \\
(47.16 \%)\end{array}$ & $\begin{array}{c}263 \\
(22.83 \%)\end{array}$ & $24.33 \%$ & $\begin{array}{c}121 \\
(7.31 \%)\end{array}$ & $\begin{array}{c}100 \\
(5.79 \%)\end{array}$ & $1.52 \%$ \\
\hline Under & $\begin{array}{c}114 \\
(7.54 \%)\end{array}$ & $\begin{array}{c}153 \\
(13.28 \%)\end{array}$ & $-5.74 \%$ & $\begin{array}{c}1,524 \\
(92.03 \%)\end{array}$ & $\begin{array}{c}1,623 \\
(93.92 \%)\end{array}$ & $-1.89 \%$ \\
\hline Total & 1,512 & 1,152 & & 1,656 & 1,728 & \\
\hline
\end{tabular}


advice has more effect on underbids (8.26/16.04) than overbids (18.07/63.38). Even when we break down the data into the former 13 periods and the latter 12 periods, (Panels (b) and (c) of Table 2), the same tendency holds. In contrast, approximately $90 \%$ of the subjects in PA and PN are likely to underbid. We also observe a 3\%-increase of sincere bidding although the advice is not true in this case. ${ }^{14}$

\subsection{Net effect of advice}

We now apply a normal approximation to examine whether the following three factors affect sincere bidding behavior: auction rule, advice, and unit. ${ }^{15}$ Suppose that sincere bidding behavior in treatment $j \in\{\mathrm{VA}, \mathrm{VN}, \mathrm{PA}, \mathrm{PN}\}$ is a realization of a random variable $X_{j}$ with the Bernoulli distribution that takes 1 (= sincere bidding) with the success rate of $p_{j}$. That is,

$$
X_{j} \equiv \begin{cases}1 & \text { with prob. } p_{j} \\ 0 & \text { with prob. } 1-p_{j}\end{cases}
$$

Let $\bar{X}_{j}$ denote the sample mean for $n_{j}$ realizations of $X_{j}$ and let

$$
S_{j} \equiv \frac{\bar{X}_{j}\left(1-\bar{X}_{j}\right)}{n_{j}}
$$

Table 3 summarizes the frequencies of sincere bidding by treatments, whether the quiz score is perfect or not, and by units. In this table, superscripts "all," "per," and "im" correspond to all subjects, the subjects whose quiz scores are perfect, and the subjects whose quiz scores are imperfect, respectively. Hereafter, capital letters indicate random variables while small letters do realized values. Table 4 summarizes the frequency of sincere bidding in the former periods (periods 1-13) and in the latter periods (periods 14-25). ${ }^{16}$

Using mainly both units' data shown in Panel (a) of Table 3, we first test whether or not the advice increases sincere bidding in each auction rule. We summarize our findings as follows:

\section{Result 2 (Advice effect).}

\footnotetext{
${ }^{14} \mathrm{~A}$ simple regression of all bids to valuations strongly shows the coefficients are 0.8032 for PA and 0.7927 for PN. For the theory of multi-unit, pay-your-bid auctions, see Lebrun and Tremblay (2003). ${ }^{15}$ See page 255 of Jacquemet and L'Haridon (2018) for the construction of our test statistics.

${ }^{16}$ We will examine whether the subject' bidding behaviors change over time in Section 4.1.
} 
Table 3: Frequency of sincere bidding by treatments, quiz scores, and units.

(a) Both units

\begin{tabular}{lcccccccc}
\hline \multirow{2}{*}{ Data } & & \multicolumn{2}{c}{ Vickrey } & $(1)$ & \multicolumn{2}{c}{ Pay-your-bid } & $(2)$ & \\
\cline { 5 - 6 } All & & VA & VN & VA-VN & PA & PN & PA-PN & $(1)-(2)$ \\
\hline \multirow{2}{*}{ Perfect } & $\bar{x}_{j}^{\text {all }}$ & 0.469 & 0.206 & $0.263^{* * *}$ & 0.083 & 0.058 & $0.025^{* * *}$ & $0.238^{* * *}$ \\
& $s_{j}^{\text {all }}$ & $\left(7.91 \times 10^{-5}\right)$ & $\left(6.81 \times 10^{-5}\right)$ & & $\left(2.21 \times 10^{-5}\right)$ & $\left(1.52 \times 10^{-5}\right)$ & & \\
\multirow{2}{*}{ Imperfect } & $\bar{x}_{j}^{\text {per }}$ & 0.523 & 0.211 & $0.312^{* * *}$ & 0.079 & 0.046 & $0.034^{* * *}$ & $0.279^{* * *}$ \\
& $s_{j}^{\text {per }}$ & $\left(1.19 \times 10^{-4}\right)$ & $\left(1.11 \times 10^{-4}\right)$ & & $\left(2.52 \times 10^{-5}\right)$ & $\left(1.53 \times 10^{-5}\right)$ & & \\
& $\bar{x}_{j}^{\text {im }}$ & 0.361 & 0.198 & $0.162^{* * *}$ & 0.104 & 0.105 & -0.002 & $0.165^{* * *}$ \\
& $s_{j}^{i m}$ & $\left(2.20 \times 10^{-4}\right)$ & $\left(1.76 \times 10^{-4}\right)$ & & $\left(1.69 \times 10^{-4}\right)$ & $\left(1.26 \times 10^{-4}\right)$ & & \\
\hline
\end{tabular}

(b) Unit 1

\begin{tabular}{|c|c|c|c|c|c|c|c|c|}
\hline \multirow[b]{2}{*}{ Data } & & \multicolumn{2}{|c|}{ Vickrey } & \multirow{2}{*}{$\begin{array}{c}(1) \\
\text { VA-VN }\end{array}$} & \multicolumn{2}{|c|}{ Pay-your-bid } & \multirow{2}{*}{$\begin{array}{c}(2) \\
P A-P N\end{array}$} & \multirow[b]{2}{*}{$(1)-(2)$} \\
\hline & & VA & VN & & PA & PN & & \\
\hline All & $\begin{array}{l}\bar{x}_{j}^{\text {all }} \\
s_{j}^{\text {all }}\end{array}$ & $\begin{array}{c}0.416 \\
\left(1.54 \times 10^{-4}\right)\end{array}$ & $\begin{array}{c}0.175 \\
\left(1.20 \times 10^{-4}\right)\end{array}$ & $0.241^{* * *}$ & $\begin{array}{c}0.020 \\
\left(1.15 \times 10^{-5}\right)\end{array}$ & $\begin{array}{c}0.006 \\
\left(3.37 \times 10^{-6}\right)\end{array}$ & $0.014^{* * *}$ & $0.227^{* * *}$ \\
\hline Perfect & $\begin{array}{l}\bar{x}_{j}^{\text {per }} \\
s_{j}^{\text {per }}\end{array}$ & $\begin{array}{c}0.463 \\
\left(2.37 \times 10^{-4}\right)\end{array}$ & $\begin{array}{c}0.176 \\
\left(1.93 \times 10^{-4}\right)\end{array}$ & $0.287^{* * *}$ & $\begin{array}{c}0.018 \\
\left(1.21 \times 10^{-5}\right)\end{array}$ & $\begin{array}{c}0.004 \\
\left(2.94 \times 10^{-6}\right)\end{array}$ & $0.014^{* * *}$ & $0.273^{* * *}$ \\
\hline Imperfect & $\begin{array}{l}\bar{x}_{j}^{i m} \\
s_{i}^{i m}\end{array}$ & $\begin{array}{c}0.322 \\
\left(4.16 \times 10^{-4}\right)\end{array}$ & $\begin{array}{c}0.173 \\
\left(3.18 \times 10^{-4}\right)\end{array}$ & $0.149^{* * *}$ & $\begin{array}{c}0.033 \\
\left(1.15 \times 10^{-4}\right)\end{array}$ & $\begin{array}{c}0.013 \\
\left(3.51 \times 10^{-5}\right)\end{array}$ & $0.019^{* *}$ & $0.129^{* * *}$ \\
\hline
\end{tabular}

(c) Unit 2

\begin{tabular}{|c|c|c|c|c|c|c|c|c|}
\hline \multirow[b]{2}{*}{ Data } & & \multicolumn{2}{|c|}{ Vickrey } & \multirow{2}{*}{$\begin{array}{c}1) \\
\mathrm{VA}-\mathrm{VN}\end{array}$} & \multicolumn{2}{|c|}{ Pay-your-bid } & \multirow{2}{*}{$\begin{array}{c}(2) \\
\text { PA-PN }\end{array}$} & \multirow[b]{2}{*}{$(1)-(2)$} \\
\hline & & VA & VN & & PA & PN & & \\
\hline All & $\begin{array}{l}\bar{x}_{j}^{\text {all }} \\
s_{j}^{\text {all }}\end{array}$ & $\begin{array}{c}0.523 \\
\left(1.58 \times 10^{-4}\right)\end{array}$ & $\begin{array}{c}0.237 \\
\left(1.51 \times 10^{-4}\right)\end{array}$ & $0.286^{* * *}$ & $\begin{array}{c}0.146 \\
\left(7.23 \times 10^{-5}\right)\end{array}$ & $\begin{array}{c}0.110 \\
\left(5.44 \times 10^{-5}\right)\end{array}$ & $0.036^{* * *}$ & $0.250^{* * *}$ \\
\hline Perfect & $\begin{array}{l}\bar{x}_{j}^{p e r} \\
s_{j}^{p e r}\end{array}$ & $\begin{array}{c}0.584 \\
\left(2.31 \times 10^{-4}\right)\end{array}$ & $\begin{array}{c}0.245 \\
\left(2.47 \times 10^{-4}\right)\end{array}$ & $0.339^{* * *}$ & $\begin{array}{c}0.141 \\
\left(8.34 \times 10^{-5}\right)\end{array}$ & $\begin{array}{c}0.087 \\
\left(5.58 \times 10^{-5}\right)\end{array}$ & $0.054^{*}$ & $0.285^{* * *}$ \\
\hline Imperfect & $\begin{array}{l}\bar{x}_{j}^{j i m} \\
s_{j}^{i m} \\
\end{array}$ & $\begin{array}{c}0.400 \\
\left(4.57 \times 10^{-4}\right) \\
\end{array}$ & $\begin{array}{c}0.222 \\
\left(3.84 \times 10^{-4}\right) \\
\end{array}$ & $0.176^{* * *}$ & $\begin{array}{c}0.175 \\
\left(5.24 \times 10^{-4}\right) \\
\end{array}$ & $\begin{array}{c}0.197 \\
\left(4.22 \times 10^{-4}\right) \\
\end{array}$ & -0.023 & $0.201^{* * *}$ \\
\hline
\end{tabular}

Notes: ${ }^{*}$ denotes significant at the $10 \%$ level, ${ }^{* *}$ at the $5 \%$ level, and ${ }^{* * *}$ at the $1 \%$ level.

Table 4: Frequency of sincere bidding by treatments, quiz scores, and periods.

(a) Former 13 periods

\begin{tabular}{|c|c|c|c|c|c|c|c|c|}
\hline \multirow[b]{2}{*}{ Data } & & \multicolumn{2}{|c|}{ Vickrey } & \multirow{2}{*}{$\begin{array}{c}(1) \\
\mathrm{VA}-\mathrm{VN}\end{array}$} & \multicolumn{2}{|c|}{ Pay-your-bid } & \multirow{2}{*}{$\begin{array}{c}(2) \\
\mathrm{PA}-\mathrm{PN}\end{array}$} & \multirow[b]{2}{*}{$(1)-(2)$} \\
\hline & & VA & VN & & PA & PN & & \\
\hline All & $\begin{array}{l}\bar{x}_{j}^{\text {all }} \\
s_{j}^{\text {all }}\end{array}$ & $\begin{array}{c}0.467 \\
\left(1.52 \times 10^{-4}\right)\end{array}$ & $\begin{array}{c}0.185 \\
\left(1.21 \times 10^{-4}\right)\end{array}$ & $0.282^{* * *}$ & $\begin{array}{c}0.093 \\
\left(4.68 \times 10^{-5}\right)\end{array}$ & $\begin{array}{c}0.058 \\
\left(2.93 \times 10^{-5}\right)\end{array}$ & $0.034^{* * *}$ & $0.248^{* * *}$ \\
\hline Perfect & $\begin{array}{l}\bar{x}_{j}^{\text {per }} \\
s_{j}^{\text {per }}\end{array}$ & $\begin{array}{c}0.510 \\
\left(2.29 \times 10^{-4}\right)\end{array}$ & $\begin{array}{c}0.182 \\
\left(1.91 \times 10^{-4}\right)\end{array}$ & $0.329^{* * *}$ & $\begin{array}{c}0.088 \\
\left(5.34 \times 10^{-5}\right)\end{array}$ & $\begin{array}{c}0.045 \\
\left(2.91 \times 10^{-5}\right)\end{array}$ & $0.043^{* * *}$ & $0.286^{* * *}$ \\
\hline Imperfect & $\begin{array}{l}\bar{x}_{j}^{i m} \\
s_{j}^{i m}\end{array}$ & $\begin{array}{c}0.379 \\
\left(4.31 \times 10^{-4}\right)\end{array}$ & $\begin{array}{c}0.190 \\
\left(3.29 \times 10^{-4}\right)\end{array}$ & $0.189^{* * *}$ & $\begin{array}{c}0.115 \\
\left(3.57 \times 10^{-4}\right)\end{array}$ & $\begin{array}{c}0.108 \\
\left(2.46 \times 10^{-4}\right)\end{array}$ & 0.008 & $0.181^{* * *}$ \\
\hline
\end{tabular}

(b) Latter 12 periods

\begin{tabular}{|c|c|c|c|c|c|c|c|c|}
\hline \multirow[b]{2}{*}{ Data } & & \multicolumn{2}{|c|}{ Vickrey } & \multirow{2}{*}{$\begin{array}{c}(1) \\
\mathrm{VA}-\mathrm{VN}\end{array}$} & \multicolumn{2}{|c|}{ Pay-your-bid } & \multirow{2}{*}{$\begin{array}{c}(2) \\
\text { PA-PN }\end{array}$} & \multirow[b]{2}{*}{$(1)-(2)$} \\
\hline & & VA & VN & & PA & PN & & \\
\hline All & $\begin{array}{l}\bar{x}_{j}^{\text {all }} \\
s_{j}^{\text {all }}\end{array}$ & $\begin{array}{c}0.472 \\
\left(1.65 \times 10^{-4}\right)\end{array}$ & $\begin{array}{c}0.228 \\
\left(1.53 \times 10^{-4}\right)\end{array}$ & $0.243^{* * *}$ & $\begin{array}{c}0.073 \\
\left(4.09 \times 10^{-5}\right)\end{array}$ & $\begin{array}{c}0.058 \\
\left(3.16 \times 10^{-5}\right)\end{array}$ & $0.015^{* *}$ & $0.228^{* * *}$ \\
\hline Perfect & $\begin{array}{l}\bar{x}_{j}^{\text {per }} \\
s_{j}^{\text {per }}\end{array}$ & $\begin{array}{c}0.537 \\
\left(2.47 \times 10^{-4}\right)\end{array}$ & $\begin{array}{c}0.242 \\
\left(2.55 \times 10^{-4}\right)\end{array}$ & $0.295^{* * *}$ & $\begin{array}{c}0.070 \\
\left(4.66 \times 10^{-5}\right)\end{array}$ & $\begin{array}{c}0.046 \\
\left(3.21 \times 10^{-5}\right)\end{array}$ & $0.024^{* * *}$ & $0.271^{* * *}$ \\
\hline Imperfect & $\begin{array}{l}\bar{x}_{j}^{i m} \\
s_{j}^{i m}\end{array}$ & $\begin{array}{c}0.341 \\
\left(4.46 \times 10^{-4}\right)\end{array}$ & $\begin{array}{c}0.206 \\
\left(3.79 \times 10^{-4}\right)\end{array}$ & $0.135^{* * *}$ & $\begin{array}{c}0.091 \\
\left(3.13 \times 10^{-4}\right)\end{array}$ & $\begin{array}{c}0.103 \\
\left(2.56 \times 10^{-4}\right)\end{array}$ & -0.012 & $0.147^{* * *}$ \\
\hline
\end{tabular}


(i) Providing advice increases sincere bidding in each auction rule when using all data. The mean increases are 26.3\% (95\% confidence interval, 24.0\% to 28.7\%) and $2.5 \%$ (95\% confidence interval, $1.3 \%$ to 3.7\%) in the Vickrey auction and in the pay-your-bid auction, respectively.

(ii) The advice is effective in the Vickrey auction even when focusing on the data of the subjects with perfect quiz scores only, or of those with imperfect quiz scores only.

(iii) The same advice is effective in the pay-your-bid auction for the subjects with perfect quiz scores rather than those with imperfect quiz scores.

Support. We first establish (i). Let $Y_{\mathrm{V}}^{\text {all }} \equiv\left(\bar{X}_{\mathrm{VA}}^{\text {all }}-\bar{X}_{\mathrm{VN}}^{\text {all }}\right)$. The test statistic is

$$
\widetilde{Y}_{\mathrm{V}}^{\text {all }} \equiv \frac{Y_{\mathrm{V}}^{\text {all }}-\mathbb{E}\left(Y_{\mathrm{V}}^{\text {all }}\right)}{\sqrt{S_{\mathrm{VA}}^{\text {all }}+S_{\mathrm{VN}}^{\text {all }}}},
$$

where $\mathbb{E}$ is the expectation operator. By the central limit theorem, $Y_{V}^{\text {all }}$ approximately follows a standardized normal distribution. Hence, in what follows, we evaluate probabilities by a standardized normal distribution unless noted otherwise. The following null hypothesis states that providing advice does not increase sincere bidding in the Vickrey auction.

Null hypothesis $\left(\boldsymbol{H}_{\mathbf{0}}^{\mathbf{1}}\right): \mathbb{E}\left(Y_{\vee}^{\text {all }}\right)=0$.

By a direct calculation, $\widetilde{y}_{\mathrm{V}}^{\text {all }}=21.71$. This yields $\operatorname{Prob}\left(\widetilde{Y}_{\mathrm{V}}^{\text {all }} \geq \widetilde{y}_{\mathrm{V}}^{\text {all }}\right)<0.0001$. Hence, advice significantly increased sincere bidding in the Vickrey auction. Moreover, the $95 \%$ confidence interval of $\mathbb{E}\left(Y_{\mathrm{V}}^{\text {all }}\right)$ is $[0.240,0.287]$.

We next consider the pay-your-bid auction. Let $Y_{\mathrm{P}}^{\text {all }} \equiv\left(\bar{X}_{\mathrm{PA}}^{\text {all }}-\bar{X}_{\mathrm{PN}}^{\text {all }}\right)$. The following null hypothesis states that providing advice does not increase sincere bidding in the pay-your-bid auction.

Null hypothesis $\left(\boldsymbol{H}_{0}^{2}\right): \mathbb{E}\left(Y_{\mathrm{P}}^{\text {all }}\right)=0$.

By a direct calculation, $\widetilde{y}_{\mathrm{P}}^{\text {all }}=4.115$. This yields $\operatorname{Prob}\left(\widetilde{Y}_{\mathrm{P}}^{\text {all }} \geq \widetilde{y}_{\mathrm{P}}^{\text {all }}\right)<0.0001$. Hence, providing advice significantly increased sincere bidding in the pay-your-bid auction although the advice is false. Therefore, this result supports a so-called experimenter demand effect (Zizzo (2009)). Moreover, the $95 \%$ confidence interval of $\mathbb{E}\left(Y_{\mathrm{P}}^{\text {all }}\right)$ is $[0.013,0.037]$. 
To establish (ii), we break the data of the Vickrey auction into two types: the subjects with perfect quiz scores or those with imperfect quiz scores. Given $h \in$ $\{p e r, i m\}, Y_{\vee}^{h}$ and $\widetilde{Y}_{\vee}^{h}$ are defined similarly. We then formulate two null hypotheses:

Null hypothesis $\left(\boldsymbol{H}_{\mathbf{0}}^{\mathbf{p}}\right): \mathbb{E}\left(Y_{\mathrm{V}}^{\text {per }}\right)=0$.

Null hypothesis $\left(\boldsymbol{H}_{\mathbf{0}}^{1 i}\right): \mathbb{E}\left(Y_{\mathrm{V}}^{i m}\right)=0$.

By a direct calculation, we obtain $\widetilde{y}_{\mathrm{V}}^{\text {per }}=20.63$ and $\widetilde{y}_{\mathrm{V}}^{i m}=8.200$, yielding $\operatorname{Prob}\left(\widetilde{Y}_{\mathrm{V}}^{\text {per }} \geq\right.$ $\left.\widetilde{y}_{\vee}^{p e r}\right)<0.0001$ and $\operatorname{Prob}\left(\widetilde{Y}_{\vee}^{i m} \geq \widetilde{y}_{\vee}^{i m}\right)<0.0001$, respectively. Hence, both $\mathbb{E}\left(Y_{\vee}^{\text {per }}\right)=0$ and $\mathbb{E}\left(Y_{\vee}^{i m}\right)=0$ are rejected.

We finally establish (iii). Given $h \in\{$ per, $i m\}, Y_{\mathrm{P}}^{h}$ and $\widetilde{Y}_{\mathrm{P}}^{h}$ are defined similarly. We also break the data of the pay-your-bid auction into the subjects with perfect quiz scores and those with imperfect quiz scores. We then formulate two null hypotheses:

Null hypothesis $\left(\boldsymbol{H}_{0}^{2 p}\right): \mathbb{E}\left(Y_{\mathrm{P}}^{\text {per }}\right)=0$.

Null hypothesis $\left(\boldsymbol{H}_{\mathbf{0}}^{2 i}\right): \mathbb{E}\left(Y_{\mathrm{P}}^{i m}\right)=0$.

Then, by a direct calculation, $\widetilde{y}_{\mathrm{P}}^{\text {per }}=5.298$ and $\widetilde{y}_{\mathrm{P}}^{i m}=-0.099$, yielding $\operatorname{Prob}\left(\widetilde{Y}_{\mathrm{P}}^{\text {per }} \geq\right.$ $\left.\widetilde{y}_{\mathrm{P}}^{\text {per }}\right)<0.0001$ and $\operatorname{Prob}\left(\widetilde{Y}_{\mathrm{P}}^{i m} \geq \widetilde{y}_{\mathrm{P}}^{i m}\right)=0.539$, respectively. Hence, $\mathbb{E}\left(Y_{\mathrm{P}}^{\text {per }}\right)=0$ is rejected, while $\mathbb{E}\left(Y_{\mathrm{P}}^{i m}\right)=0$ is accepted. Thus, we establish (iii).

The advice effect on the pay-your-bid auction reported in Result 2 should be considered as an experimenter demand effect, since the advice is false in that auction. Thus, there is a possibility that the advice effect in the Vickrey auction might also be an experimenter demand effect. However, Result 2 also reports that the advice effect in the Vickrey auction is much higher than that in the pay-your-bid auction. An excess of effect over the experimenter demand effect is considered as a "net effect" of advice to promote sincere bidding in the Vickrey auction. We next test whether the advice in the Vickrey auction has a net effect. We call its effect the net advice effect.

Since the advice provided in both auctions is identical, the experimenter demand effects would also be similar in both auctions. Moreover, since the advice is false in the pay-your-bid auction, its advice effect is an all experimenter demand effect. Thus, we assume that the net advice effect in the Vickrey auction can be measured by the difference in advice effects on the two auctions. We test the net advice effect in the Vickrey auction under this assumption.

Result 3 (Net advice effect). Providing advice increases the rate of sincere bidding much more in the Vickrey auction compared with the pay-your-bid auction, with the mean increase of $23.8 \%$ (95\% confidence interval, 21.2\% to 26.5\%). 
Support. We follow a difference-in-difference type argument. Let $Z^{\text {all }}=\left(Y_{\mathrm{V}}^{\text {all }}-Y_{\mathrm{P}}^{\text {all }}\right)$. The test statistic is

$$
\widetilde{Z}^{\text {all }} \equiv \frac{Z^{\text {all }}-\mathbb{E}\left(Z^{\text {all }}\right)}{\sqrt{S_{\mathrm{VA}}^{\text {all }}+S_{\mathrm{VN}}^{\text {all }}+S_{\mathrm{PA}}^{\text {all }}+S_{\mathrm{PN}}^{\text {all }}}} .
$$

We formulate the null hypothesis as follows:

Null hypothesis $\left(\boldsymbol{H}_{0}^{\mathbf{3}}\right): \mathbb{E}\left(Z^{\text {all }}\right)=0$.

By a direct calculation, $\widetilde{z}^{\text {all }}=17.54$. This yields $\operatorname{Prob}\left(\widetilde{Z}^{\text {all }} \geq \widetilde{z}^{\text {all }}\right)<0.0001$. Moreover, the $95 \%$ confidence interval of $\mathbb{E}\left(Z^{\text {all }}\right)$ is $[0.212,0.265]$.

The difference, $23.8 \%$, of the advice effects in the two auctions is considered as the net advice effect on the Vickrey auction. Many authors investigate why subjects do not bid sincerely in the Vickrey auction by proposing alternative explanations. Result 3 suggests that a considerable amount of such behavior might be mitigated by providing advice that helps to understand the strategy-proofness property of the Vickrey auction.

We finally test whether quiz scores affect the responsiveness to advice in the Vickrey auction. The following result demonstrates that the responsiveness to advice depends on the quiz scores in the Vickrey auction.

Result 4 (Relationship between quiz scores and advice effects). Within the Vickrey auction, the subjects with perfect quiz scores are more responsive to advice than the subjects with imperfect quiz scores. The mean difference between the two groups in terms of an increase in the rate of sincere bidding is 15.0\% (95\% confidence interval, $10.1 \%$ to $20.0 \%)$.

Support. Let $W_{\mathrm{V}}=\left(Y_{\mathrm{V}}^{\text {per }}-Y_{\mathrm{V}}^{\text {im }}\right)$. The test statistic is

$$
\widetilde{W}_{\mathrm{V}} \equiv \frac{W_{\mathrm{\vee}}-\mathbb{E}\left(W_{\mathrm{V}}\right)}{\sqrt{S_{\mathrm{VA}}^{p e r}+S_{\mathrm{VN}}^{p e r}+S_{\mathrm{VA}}^{i m}+S_{\mathrm{VN}}^{i m}}} .
$$

We formulate the null hypothesis as follows:

Null hypothesis $\left(\boldsymbol{H}_{\mathbf{0}}^{4}\right): \mathbb{E}\left(W_{\mathrm{V}}\right)=0$.

By a direct calculation, $\widetilde{w}_{\vee}=5.977$. This yields $\operatorname{Prob}\left(\widetilde{W}_{\vee} \geq \widetilde{w}_{\mathrm{V}}\right)<0.0001$. Moreover, the $95 \%$ confidence interval of $\mathbb{E}\left(W_{\mathrm{V}}\right)$ is [0.101, 0.200].

Result 4 suggests that subjects who properly understand the rule of the Vickrey auction tend to bid sincerely under the advice than others who do not so. 
Table 5: Frequency of sincere bidding in period one by treatments and quiz scores.

\begin{tabular}{|c|c|c|c|c|c|c|c|c|}
\hline \multirow[b]{2}{*}{ Data } & & \multicolumn{2}{|c|}{ Vickrey } & \multirow{2}{*}{$\begin{array}{c}(1) \\
V A-V N\end{array}$} & \multicolumn{2}{|c|}{ Pay-your-bid } & \multirow{2}{*}{$\begin{array}{c}(2) \\
\mathrm{PA}-\mathrm{PN}\end{array}$} & \multirow[b]{2}{*}{$(1)-(2)$} \\
\hline & & VA & VN & & PA & PN & & \\
\hline All & $\begin{array}{l}\bar{x}_{j}^{\text {all }} \\
s_{i}^{\text {all }}\end{array}$ & $\begin{array}{c}0.468 \\
\left(1.98 \times 10^{-3}\right)\end{array}$ & $\begin{array}{c}0.188 \\
\left(1.59 \times 10^{-3}\right)\end{array}$ & $0.280^{* * *}$ & $\begin{array}{c}0.123 \\
\left(7.83 \times 10^{-4}\right)\end{array}$ & $\begin{array}{c}0.021 \\
\left(1.42 \times 10^{-4}\right)\end{array}$ & $0.102^{* * *}$ & $0.178^{* * *}$ \\
\hline Perfect & $\begin{array}{l}\bar{x}_{j}^{\text {per }} \\
s_{j}^{\text {per }}\end{array}$ & $\begin{array}{c}0.512 \\
\left(2.97 \times 10^{-3}\right)\end{array}$ & $\begin{array}{c}0.233 \\
\left(2.98 \times 10^{-3}\right)\end{array}$ & $0.279^{* * *}$ & $\begin{array}{c}0.138 \\
\left(1.02 \times 10^{-3}\right)\end{array}$ & $\begin{array}{c}0.026 \\
\left(2.25 \times 10^{-4}\right)\end{array}$ & $0.112^{* * *}$ & $0.167^{* *}$ \\
\hline Imperfect & $\begin{array}{l}\bar{x}_{j}^{i m} \\
s_{j}^{i m}\end{array}$ & $\begin{array}{c}0.381 \\
\left(5.61 \times 10^{-3}\right)\end{array}$ & $\begin{array}{c}0.111 \\
\left(2.75 \times 10^{-3}\right)\end{array}$ & $0.270^{* * *}$ & $\begin{array}{c}0.046^{b)} \\
\left(1.97 \times 10^{-3}\right)\end{array}$ & $\begin{array}{c}0 \\
(0)\end{array}$ & 0.046 & $0.225^{* *}$ \\
\hline
\end{tabular}

Notes: a) ${ }^{*}$ denotes significant at the $10 \%$ level, ${ }^{* *}$ at the $5 \%$ level, and ${ }^{* * *}$ at the $1 \%$ level; and b) The number of observations is no more than 30 .

Remark 1. When we restrict our attention to the first period only and use both units' data, as shown in Table $5, H_{0}^{1}, H_{0}^{2}$, and $H_{0}^{3}$ are again rejected at the $10 \%$ significance level except for the cases including imperfectly scored subjects in the pay-your-bid auction, where the sample size is smaller than 30 , while $H_{0}^{4}$ is accepted.

\subsection{Efficiency}

Our efficiency measure is due to Kagel and Levine (2009). ${ }^{17}$ In one game, if $i$ is the winner with the highest bid and if $j$ is the winner with the second-highest bid, then the observed efficiency ratio $r$ is given by $\frac{v_{i}^{1}+v_{j}^{1}}{v[1]+v[2]}$ if $i \neq j$ and by $\frac{v_{i}^{1}+v_{i}^{2}}{v[1]+v[2]}$ if $i=j$, where $v[1], v[2]$ denote the two highest units among six valuations $\left(v_{1}^{1}, v_{1}^{2}, v_{2}^{1}, v_{2}^{2}, v_{3}^{1}, v_{3}^{2}\right)$. The efficiency ratio of the full or part of a treatment is the average of the efficiency ratios in the games in the full treatment or part of the treatment.

As in Section 3.3, we again normally approximated to examine the effect of auction rules, advice, and experience on efficiency. Suppose the efficiency ratio $r$ in treatment $j \in\{\mathrm{VA}, \mathrm{VN}, \mathrm{PA}, \mathrm{PN}\}$ is a realization of a random variable $R_{j}$ with mean $\mathbb{E}\left(R_{j}\right) \in[0,1]$ and variance $\operatorname{Var}\left(R_{j}\right)$. Let $\bar{R}_{j}$ denote the sample mean for $n_{j}^{\prime}$ realizations of $R_{j}$. Let

$$
T_{j} \equiv \frac{\sum_{k=1}^{n_{j}}\left(R_{j k}-\bar{R}_{j}\right)^{2} /\left(n_{j}^{\prime}-1\right)}{n_{j}^{\prime}} .
$$

Superscripts " $a p$, " " $f p$," and " $l p$ " correspond to all periods, the former periods (periods 1-13), and the latter periods (periods 14-25), respectively. Table 6 summarizes the results on efficiency with a focus on experience. ${ }^{18}$ In Table 6 , the upper (respectively,

\footnotetext{
${ }^{17}$ See also Kwasnica and Sherstyuk (2013).

${ }^{18}$ Englemann and Grimm (2009) compare the Vickrey auction with the pay-your-bid auction by conducting an experiment, where two units of an item are auctioned to two bidders with flat demand. Their experimental results are similar to ours in regard to the comparison of the efficiency ratios in the two auctions.
} 
Table 6: Efficiency by treatments and periods.

\begin{tabular}{|c|c|c|c|c|c|c|c|c|}
\hline \multirow[b]{2}{*}{ Data } & & \multicolumn{2}{|c|}{ Vickrey } & \multirow{2}{*}{$\begin{array}{c}(1) \\
V A-V N\end{array}$} & \multicolumn{2}{|c|}{ Pay-your-bid } & \multirow{2}{*}{$\begin{array}{c}(2) \\
\mathrm{PA}-\mathrm{PN}\end{array}$} & \multirow[b]{2}{*}{$(1)-(2)$} \\
\hline & & VA & VN & & PA & PN & & \\
\hline All periods & $\begin{array}{l}\bar{r}_{j}^{a p} \\
t_{j}^{a p}\end{array}$ & $\begin{array}{c}0.977 \\
\left(8.95 \times 10^{-6}\right)\end{array}$ & $\begin{array}{c}0.967 \\
\left(1.62 \times 10^{-5}\right)\end{array}$ & $0.010^{* *}$ & $\begin{array}{c}0.990 \\
\left(1.36 \times 10^{-6}\right)\end{array}$ & $\begin{array}{c}0.988 \\
\left(1.36 \times 10^{-6}\right)\end{array}$ & 0.002 & $0.009^{*}$ \\
\hline Periods $1-13$ & $\begin{array}{c}\bar{r}_{j}^{f p} \\
t_{j}^{f p}\end{array}$ & $\begin{array}{c}0.970 \\
\left(2.32 \times 10^{-5}\right)\end{array}$ & $\begin{array}{c}0.956 \\
\left(4.59 \times 10^{-5}\right)\end{array}$ & $0.015^{* *}$ & $\begin{array}{c}0.991 \\
\left(2.27 \times 10^{-6}\right)\end{array}$ & $\begin{array}{c}0.989 \\
\left(2.67 \times 10^{-6}\right)\end{array}$ & 0.002 & $0.013^{*}$ \\
\hline Periods $14-25$ & $\begin{array}{l}\bar{r}_{j}^{l p} \\
t_{j}^{l p} \\
\end{array}$ & $\begin{array}{c}0.984 \\
\left(1.13 \times 10^{-5}\right) \\
\end{array}$ & $\begin{array}{c}0.978 \\
\left(1.53 \times 10^{-5}\right) \\
\end{array}$ & 0.006 & $\begin{array}{c}0.989 \\
\left(3.26 \times 10^{-6}\right) \\
\end{array}$ & $\begin{array}{c}0.988 \\
\left(2.76 \times 10^{-6}\right) \\
\end{array}$ & 0.001 & 0.004 \\
\hline
\end{tabular}

middle, bottom) panel collects the results obtained for all periods (respectively, periods 1-13, periods 14-25).

Result 5 (Advice effects on efficiency). Providing advice improves efficiency in the Vickrey auction, particularly in the former 13 periods.

Support. Given $h \in\{a p, f p, l p\}$, let $U_{\mathrm{V}}^{h}=\left(\bar{R}_{\mathrm{VA}}^{h}-\bar{R}_{\mathrm{VN}}^{h}\right)$. The test statistic is

$$
\widetilde{U}_{\mathrm{V}}^{h} \equiv \frac{U_{\mathrm{V}}^{h}-\mathbb{E}\left(U_{\mathrm{V}}^{h}\right)}{\sqrt{T_{\mathrm{VN}}^{h}+T_{\mathrm{VN}}^{h}}} .
$$

The following hypothesis states that providing advice does not increase efficiency within the Vickrey auction.

Null hypothesis $\left(\boldsymbol{H}_{\mathbf{0}}^{\mathbf{5}}\right): \mathbb{E}\left(U_{\vee}^{a p}\right)=0$.

By a direct calculation, $\widetilde{u}_{\mathrm{V}}^{a p}=2.054$. This yields $\operatorname{Prob}\left(\widetilde{U}_{\mathrm{V}}^{a p} \geq \widetilde{u}_{\mathrm{V}}^{a p}\right)=0.020$. Therefore, advice significantly increased efficiency in the Vickrey auction.

To obtain further insights, we break the data into two types: periods 1-13 and 14-25. We then formulate two null hypotheses:

Null hypothesis $\left(\boldsymbol{H}_{\mathbf{0}}^{\mathbf{5 f}}\right): \mathbb{E}\left(U_{\mathrm{V}}^{f p}\right)=0$.

Null hypothesis $\left(\boldsymbol{H}_{\mathbf{0}}^{5 l}\right): \mathbb{E}\left(U_{\mathrm{V}}^{l p}\right)=0$.

Then, we obtain $\widetilde{u}_{\mathrm{V}}^{f p}=1.769$ and $\widetilde{u}_{\mathrm{V}}^{l p}=1.066$, yielding $\operatorname{Prob}\left(\widetilde{U}_{\mathrm{V}}^{f p} \geq \widetilde{u}_{\mathrm{V}}^{f p}\right)=0.038$ and $\operatorname{Prob}\left(\widetilde{U}_{\mathrm{V}}^{l p} \geq \widetilde{u}_{\mathrm{V}}^{l p}\right)=0.143$, respectively. Hence, $\mathbb{E}\left(U_{\mathrm{V}}^{f p}\right)=0$ is rejected, while $\mathbb{E}\left(U_{\mathrm{V}}^{l p}\right)=0$ is not rejected.

Result 5 suggests that improvements in the efficiency of the Vickrey auction occurs mainly when subjects are less experienced. 
Result 6 (Relative effect of advice on efficiency). The relative effect of the advice of strategy-proofness on the efficiency of the Vickrey auction compared with the payyour-bid auction exists, particularly in early periods.

Support. We again apply the difference-in-difference technique analogously to Result 4. Let $Q^{a p}=\left(U_{\mathrm{V}}^{a p}-U_{\mathrm{P}}^{a p}\right)$. The test statistic is

$$
\widetilde{Q}^{a p} \equiv \frac{Q^{a p}-\mathbb{E}\left(Q^{a p}\right)}{\sqrt{T_{\mathrm{VA}}^{a p}+T_{\mathrm{VN}}^{a p}+T_{\mathrm{PA}}^{a p}+T_{\mathrm{PN}}^{a p}}} .
$$

We formulate the null hypothesis as follows:

Null hypothesis $\left(\boldsymbol{H}_{\mathbf{0}}^{\mathbf{6}}\right): \mathbb{E}\left(Q^{a p}\right)=0$.

By a direct calculation, $\widetilde{q}^{a p}=1.629$. This yields $\operatorname{Prob}\left(\widetilde{Q}^{a p} \geq \widetilde{q}^{a p}\right)=0.052$. Again, we break the data into two: periods $1-13$ and 14-25. Given $h \in\{f p, l p\}, Q^{h}$ and $\widetilde{Q}^{h}$ are defined similarly. We then formulate two null hypotheses:

Null hypothesis $\left(\boldsymbol{H}_{\mathbf{0}}^{\mathbf{6 f}}\right): \mathbb{E}\left(Q^{f p}\right)=0$.

Null hypothesis $\left(\boldsymbol{H}_{\mathbf{0}}^{6 l}\right): \mathbb{E}\left(Q^{l p}\right)=0$.

Then, we obtain $\widetilde{q}^{f p}=1.454$ and $\widetilde{q}^{l p}=0.770$, yielding $\operatorname{Prob}\left(\widetilde{Q}^{f p} \geq \widetilde{q}^{f p}\right)=0.073$ and $\operatorname{Prob}\left(\widetilde{Q}^{l p} \geq \widetilde{q}^{l p}\right)=0.221$, respectively. Hence, $\mathbb{E}\left(Q^{f p}\right)=0$ is rejected at the $10 \%$ significance level, while $\mathbb{E}\left(Q^{l p}\right)=0$ is not rejected.

Result 6 suggests that a relative improvement in the efficiency of the Vickrey auction compared with the pay-your-bid auction occurs mainly when subjects are less experienced.

Remark 2. We also tested the same hypotheses using an alternative way of defining efficiency, where we care only whether efficient allocation is realized in a group observation. We found a significant increase in the efficiency of the Vickrey auction for all periods, the former periods, and the latter periods. That is, Result 6 is replicated. See Table 9 in Appendix A.

\section{Discussion}

\subsection{Regression analysis of sincere bidding}

We perform a regression analysis to check the robustness of the results. Almost all results are confirmed. The dependent variable is a dummy variable of sincere bidding, 
which takes 1 if subject $i$ in period $t$ bids sincerely. The three independent variables are the same variables we examined independently in the previous section:

- Advice is a dummy for treatments with advice;

- Latter is a dummy for periods more than 13; and

- Perfect is a dummy for subjects with a perfect score in the quiz.

We also included the interaction terms of these three variables. Table 7 summarizes the results from linear probability models of sincere bidding by auction rules and units. For each auction rule and unit, we run three regressions with different specifications.

The highlights of the linear probability model regression results are as follows. ${ }^{19}$

- Vickrey: Both Advice and Advice $\times$ Perfect in specifications from (1) to (6) have the coefficients of $15 \%$ or more for both units, supporting Result 2 and Result 4. Moreover, the insignificant effect in Latter and Advice $\times$ Latter in specifications (3) and (6) suggests that the rate of sincere bidding is stable in time, and the advice quickly improves the rate of sincere bidding in earlier periods. ${ }^{20}$ This quick effect of advice is consistent with Table 4. Finally, the comparison of Perfect and Advice $\times$ Perfect in specifications (3) and (6) suggests that advice has quite a similar effect on sincere bidding across units, given the level of understanding of the auction rule.

- Pay-your-bid: Specifications (9) and (12) with negative coefficients of Perfect confirm that the subjects become less likely to bid sincerely as they understand the auction rule correctly. This is consistent with Table 3.

The literature reports mixed results on whether the second price auction subjects learn to bid sincerely from experiencing losses owing to overbidding. For example, Cooper and Fang (2008) observe learning, while Harstad (2000) do not. Using an additional regression, we do not find such evidence in any of two auction rules, and this is consistent with Harstad (2000).

\footnotetext{
${ }^{19}$ See Angrist and Pischke (2008) for the wide applicability of the linear probability model.

${ }^{20}$ Together with the insignificant effect in Latter $\times$ Perfect and Advice $\times$ Latter $\times$ Perfect, this result suggests that the learning process is similar between groups with different levels of understanding of auction rules.
} 
Table 7: Regression analysis of sincere bidding.

(a) Vickrey

\begin{tabular}{|c|c|c|c|c|c|c|}
\hline & \multicolumn{3}{|c|}{ Unit 1} & \multicolumn{3}{|c|}{ Unit 2} \\
\hline & $(1)$ & $(2)$ & (3) & (4) & (5) & (6) \\
\hline Advice & $0.149^{* * *}$ & $0.270^{* * *}$ & $0.178^{* * *}$ & $0.178^{* * *}$ & $0.294^{* * *}$ & $0.200^{* * *}$ \\
\hline Aavice & $(0.029)$ & $(0.024)$ & $(0.040)$ & $(0.030)$ & $(0.025)$ & $(0.041)$ \\
\hline Perfect & $\begin{array}{c}0.003 \\
(0.027)\end{array}$ & & $\begin{array}{c}-0.021 \\
(0.037)\end{array}$ & $\begin{array}{c}0.023 \\
(0.028)\end{array}$ & & $\begin{array}{c}0.004 \\
(0.038)\end{array}$ \\
\hline Advice $\times$ Perfect & $\begin{array}{l}0.138^{* * *} \\
(0.036)\end{array}$ & & $\begin{array}{l}0.140^{* * *} \\
(0.049)\end{array}$ & $\begin{array}{l}0.161^{* * *} \\
(0.037)\end{array}$ & & $\begin{array}{l}0.140^{* * *} \\
(0.052)\end{array}$ \\
\hline Latter & & $\begin{array}{c}0.044^{*} \\
(0.026)\end{array}$ & $\begin{array}{c}0.014 \\
(0.042)\end{array}$ & & $\begin{array}{c}0.042 \\
(0.027)\end{array}$ & $\begin{array}{c}0.018 \\
(0.044)\end{array}$ \\
\hline Advice $\times$ Latter & & $\begin{array}{r}-0.060^{*} \\
(0.034)\end{array}$ & $\begin{array}{c}-0.061 \\
(0.057)\end{array}$ & & $\begin{array}{c}-0.017 \\
(0.036)\end{array}$ & $\begin{array}{c}-0.047 \\
(0.060)\end{array}$ \\
\hline Latter $\times$ Perfect & & & $\begin{array}{c}0.048 \\
(0.053)\end{array}$ & & & $\begin{array}{c}0.039 \\
(0.055)\end{array}$ \\
\hline Advice $\times$ Latter $\times$ Perfect & & & $\begin{array}{r}-0.003 \\
(0.071)\end{array}$ & & & $\begin{array}{c}0.042 \\
(0.074)\end{array}$ \\
\hline Constant & $\begin{array}{l}0.173^{* * *} \\
(0.021)\end{array}$ & $\begin{array}{l}0.154^{* * *} \\
(0.018)\end{array}$ & $\begin{array}{l}0.167^{* * *} \\
(0.029)\end{array}$ & $\begin{array}{l}0.222^{* * *} \\
(0.022)\end{array}$ & $\begin{array}{l}0.216^{* * *} \\
(0.019)\end{array}$ & $\begin{array}{l}0.214^{* * *} \\
(0.030)\end{array}$ \\
\hline Observations & 2,775 & 2,775 & 2,775 & 2,775 & 2,775 & 2,775 \\
\hline Adjusted $R^{2}$ & 0.077 & 0.067 & 0.077 & 0.101 & 0.084 & 0.102 \\
\hline \multicolumn{7}{|c|}{ (b) Pay-your-bid } \\
\hline & \multicolumn{3}{|c|}{ Unit 1} & \multicolumn{3}{|c|}{ Unit 2} \\
\hline & (7) & (8) & (9) & (10) & (11) & (12) \\
\hline Advice & $\begin{array}{c}0.019^{* *} \\
(0.009)\end{array}$ & $\begin{array}{c}0.010^{*} \\
(0.005)\end{array}$ & $\begin{array}{c}0.000 \\
(0.012)\end{array}$ & $\begin{array}{c}-0.023 \\
(0.026)\end{array}$ & $\begin{array}{c}0.058^{* * *} \\
(0.016)\end{array}$ & $\begin{array}{c}0.015 \\
(0.037)\end{array}$ \\
\hline Perfect & $\begin{array}{c}-0.009 \\
(0.007)\end{array}$ & & $\begin{array}{r}-0.016^{*} \\
(0.009)\end{array}$ & $\begin{array}{c}-0.110^{* * *} \\
(0.019)\end{array}$ & & $\begin{array}{c}-0.109^{* * *} \\
(0.027)\end{array}$ \\
\hline Advice $\times$ Perfect & $\begin{array}{c}-0.006 \\
(0.010)\end{array}$ & & $\begin{array}{c}0.013 \\
(0.014)\end{array}$ & $\begin{array}{l}0.076^{* * *} \\
(0.029)\end{array}$ & & $\begin{array}{c}0.058 \\
(0.040)\end{array}$ \\
\hline Latter & & $\begin{array}{c}-0.003 \\
(0.005)\end{array}$ & $\begin{array}{c}-0.015 \\
(0.012)\end{array}$ & & $\begin{array}{c}0.002 \\
(0.016)\end{array}$ & $\begin{array}{l}0.005 \\
(0.034)\end{array}$ \\
\hline Advice $\times$ Latter & & $\begin{array}{c}0.008 \\
(0.008)\end{array}$ & $\begin{array}{c}0.039^{* *} \\
(0.018)\end{array}$ & & $\begin{array}{c}-0.046^{* *} \\
(0.022)\end{array}$ & $\begin{array}{r}-0.079 \\
(0.053)\end{array}$ \\
\hline Latter $\times$ Perfect & & & $\begin{array}{c}0.015 \\
(0.013)\end{array}$ & & & $\begin{array}{c}-0.004 \\
(0.039)\end{array}$ \\
\hline Advice $\times$ Latter $\times$ Perfect & & & $\begin{array}{r}-0.038^{*} \\
(0.020)\end{array}$ & & & $\begin{array}{c}0.039 \\
(0.058)\end{array}$ \\
\hline Constant & $\begin{array}{l}0.013^{* *} \\
(0.006)\end{array}$ & $\begin{array}{c}0.007^{* *} \\
(0.004)\end{array}$ & $\begin{array}{l}0.021^{* *} \\
(0.008)\end{array}$ & $\begin{array}{l}0.197^{* * *} \\
(0.017)\end{array}$ & $\begin{array}{l}0.109^{* * *} \\
(0.011)\end{array}$ & $\begin{array}{l}0.195^{* * *} \\
(0.024)\end{array}$ \\
\hline Observations & 3,525 & 3,525 & 3,525 & 3,525 & 3,525 & 3,525 \\
\hline Adjusted $R^{2}$ & 0.005 & 0.003 & 0.005 & 0.012 & 0.004 & 0.013 \\
\hline
\end{tabular}

Notes: ${ }^{*}$ denotes significant at the $10 \%$ level, ${ }^{* *}$ at the $5 \%$ level, and ${ }^{* * *}$ at the $1 \%$ level. 


\subsection{How did subjects perceive advice?}

We examined how many subjects believed the advice in VA by employing a post experimental questionnaire. The questionnaire asks subjects whether they believe the advice, and if yes, since when they started believing it. Subjects chose one from four answers:

(a) Believed the advice before practice periods;

(b) Believed the advice after practice periods but before real periods;

(c) Believed the advice during real periods; and

(d) Never believed.

In VA, the number of subjects who chose (a), (b), (c), and (d) is, respectively, 13, 14, 14, and 22. Thus, in VA, 41 subjects believed the advice, and 22 did not.

We categorized the subjects in VA into two groups - agents who believed (a, b, c) and agents who never believed (d) - and ran normal approximation parametric tests for group comparison. We obtained two reasonable results:

1. The VA subjects who believed the advice bid significantly more sincerely compared with the VA subjects who never believed the advice $(60.2 \%$ and $22.2 \%$, respectively; $z=22.97, p<0.001)$; and

2. The rate of sincere bidding among the VA subjects who never believed the advice is not significantly different from that of all VN subjects $(22.2 \%$ and $20.6 \%$, respectively; $z=1.238, p=0.215$ ).

These results suggest that providing advice is likely to increase sincere bids when subjects believe them, and that providing advice makes subjects bid more sincerelynot because subjects are influenced by the experimenter demand effect, but because subjects believe the advice.

Remark 3. Incidentally, in PA, the number of subjects who chose (a), (b), (c), and (d) was, respectively, 3, 1, 0, and 65, that is, 4 subjects believed the advice, and 65 never did. We also find that there is no statistical difference in the rate of sincere bidding between two groups in PA. Moreover, the rate of sincere bidding among those who never believed the advice was significantly higher than the overall rate of sincere bidding in PN. 
Table 8: Average bidder's payoff and average seller's revenue per auction.

(a) Bidder's payoff

\begin{tabular}{|c|c|c|c|c|c|c|c|}
\hline \multirow[b]{2}{*}{ Data } & & \multicolumn{2}{|c|}{ Vickrey } & \multirow[b]{2}{*}{ VA-VN } & \multicolumn{2}{|c|}{ Pay-your-bid } & \multirow[b]{2}{*}{ PA-PN } \\
\hline & & VA & VN & & PA & PN & \\
\hline All p & $\begin{array}{l}\bar{\pi}_{j}^{a p} \\
\xi_{i}^{a p}\end{array}$ & $\begin{array}{c}136.844 \\
(32.174)\end{array}$ & $\begin{array}{l}122.292 \\
(40.912)\end{array}$ & $14.553^{*}$ & $\begin{array}{l}82.829 \\
(6.448)\end{array}$ & $\begin{array}{l}89.928 \\
(6.901)\end{array}$ & $-7.099^{*}$ \\
\hline Peric & $\begin{array}{l}\bar{\pi}_{j}^{f p} \\
\xi_{j}^{f p}\end{array}$ & $\begin{array}{l}132.247 \\
(67.765)\end{array}$ & $\begin{array}{l}115.000 \\
(86.076)\end{array}$ & 17.247 & $\begin{array}{c}78.997 \\
(11.478)\end{array}$ & $\begin{array}{c}83.301 \\
(12.388)\end{array}$ & -4.305 \\
\hline Period 1 & $\begin{array}{l}\bar{\pi}_{j}^{l p} \\
\xi_{j}^{l p}\end{array}$ & $\begin{array}{l}141.825 \\
(60.139)\end{array}$ & $\begin{array}{l}130.191 \\
(76.487)\end{array}$ & 11.634 & $\begin{array}{c}86.981 \\
(14.493)\end{array}$ & $\begin{array}{c}97.106 \\
(15.317)\end{array}$ & $-10.126^{*}$ \\
\hline
\end{tabular}

(b) Seller's revenue

\begin{tabular}{lccccccr}
\hline \multirow{2}{*}{ Data } & & \multicolumn{3}{c}{ Vickrey } & & \multicolumn{3}{c}{ Pay-your-bid } & \\
\cline { 3 - 4 } \cline { 6 - 7 } All periods & $\bar{\pi}_{j}^{a p}$ & 1139.410 & 1125.875 & 13.535 & 1303.704 & 1288.700 & 15.004 \\
& $\xi_{j}^{a p}$ & $(226.595)$ & $(465.283)$ & & $(56.924)$ & $(64.599)$ & \\
\hline \multirow{2}{*}{ Periods 1-13 } & $\bar{\pi}_{j}^{f p}$ & 1144.689 & 1142.933 & 1.756 & 1313.211 & 1303.397 & 9.813 \\
& $\xi_{j}^{f p}$ & $(604.420)$ & $(882.481)$ & & $(120.829)$ & $(143.281)$ & \\
\multirow{2}{*}{ Periods 14-25 } & $\bar{\pi}_{j}^{l p}$ & 1133.690 & 1107.396 & 26.295 & 1293.406 & 1272.778 & 20.628 \\
& $\xi_{j}^{l p}$ & $(599.881)$ & $(985.408)$ & & $(104.943)$ & $(110.987)$ & \\
\hline
\end{tabular}

Notes: a) * denotes significant at the $10 \%$ level, ${ }^{* *}$ at the $5 \%$ level, and ${ }^{* * *}$ at the $1 \%$ level; and b) Given $j \in\{\mathrm{VA}, \mathrm{VN}, \mathrm{PA}, \mathrm{PN}\}$, let $\bar{\Pi}_{j}$ denote denote the sample mean for $n_{j}^{\prime}$ realizations of an observation of the bidder's payoff (or the seller's revenue) $\Pi_{j} . \Xi_{j}$ is defined similarly to $T_{j}$ introduced in Section 3.4.

\subsection{Bidders' payoffs and seller's revenue}

In this section, we ask whether the advice affects bidders' payoffs and the seller's revenue in each auction rule. Table 8 summarizes the results on bidders' payoffs and the seller's revenue. We then make the following observations.

\section{Result 7 (Bidders' payoffs and seller's revenue).}

(i) The advice marginally increases (respectively, decreases) the bidder's payoff per auction in the Vickrey (respectively, pay-your-bid) auction using all data.

(ii) The advice does not affect the seller's revenue.

The increase in bidders' payoffs in the Vickrey auction is consistent with the efficiency gain we reported in Section 3.4. See, also, Online Appendix C for the comparison of different auction rules in regard to bidders' payoffs and seller's revenue. 


\subsection{Ausubel auction}

We further conducted an experiment to test the effect of advice for the Ausubel auction (Ausubel (2004)). ${ }^{21}$ The Ausubel auction, which is an ascending bid auction, is considered a dynamic version of the Vickrey auction. That is, the equilibrium outcomes of the former and the latter are equivalent. ${ }^{22}$ It is well known that, in the Ausubel auction, sincere bidding, where bidders may reduce their demand for units at prices equal to their valuations for these units, is not a weakly dominant strategy. In this sense, the Ausubel auction is not strategy-proof. However, in the Ausubel auction, sincere bidding is an ex post equilibrium (Ausubel (2004); Okamoto (2018)). Therefore, one might think that providing advice would improve the performance of the Ausubel auction, as with the Vickrey auction. We then provided the following advice to subjects in our experiment:

"The following advice is about the auction in which you are participating. Please consider carefully whether this advice is true or false. It is completely up to you whether you follow the advice.

You can maximize your earnings by reducing your demands at your valuations as they are, regardless of the prices at which others reduce their demands."

We have two types of treatments: the Ausubel auction with advice and without advice. ${ }^{23}$ In our experiment, almost half of the subjects had a perfect score in the quiz of the Ausubel auction. We then confirmed that the advice effect exists in the Ausubel auction, that is, providing advice increases sincere bidding in the Ausubel auction. In addition, as with the Vickrey auction, we observed that subjects who understand the rule of the Ausubel auction well are likely to bid sincerely on the basis of advice than others who do not. However, providing advice does not increase (value-based) efficiency in the Ausubel auction. ${ }^{24}$

We compare our Ausubel auction data with our Vickrey auction data. On doing so, we find that, when the advice is provided, the rate of sincere bidding for nonwinning bids is significantly higher in the Vickrey auction compared with the Ausubel

\footnotetext{
${ }^{21}$ We thank an anonymous referee for suggesting this experiment.

${ }^{22}$ Online Appendix B provides the more formal definition of the Ausubel auction.

${ }^{23}$ To compare the results of the Vickrey auction and those of the Ausubel auction, the settings for each treatment are identical to the setting for the Vickrey experiment. See Online Appendix B for the details of our experimental procedures. The full set of experimental instructions (including screen shots and quiz) for these two treatments can be found in Online Appendix K-P.

${ }^{24}$ If we evaluate efficiency using the binary efficiency, shown in Online Appendix B, the improvement is marginally significant in the former periods.
} 
auction. ${ }^{25}$ Although Kagel and Levin (2009) observe that the dynamic format brings sincere bidding more in line with theory than the static format, our experimental result suggests that providing advice can exceed such a "dynamic" effect and reverse the order. The logic behind this is as follows: Providing advice improves sincere bidding in the Ausubel auction mainly through the bids for the first unit and does so for both units in the Vickrey auction. Thus, the total improvement in sincere biding is much larger in the Vickrey auction.

We formally state these results and provide the statistical analysis of these results in Online Appendix B.

\section{Conclusion}

We experimentally showed that introducing advice on strategy-proofness leads to a higher rate of sincere bidding in a multi-unit static Vickrey auction. Without this advice, the rate of sincere bidding in our experiment is similar to rates observed in previous studies. The same piece of advice has effects not only in the Vickrey auction, but also in the pay-your-bid auction. The latter effect is attributed to the so-called experimenter demand effect (Zizzo (2009)). To detect whether the advice has an effect beyond the experimenter demand effect, which we call the net advice effect, we compared the effects in the two auctions. We found that a large net advice effect exists in the Vickrey auction.

Since overbidding in the Vickrey auction has been widely observed in the literature (Kagel and Levin (1993); Garratt et al. (2012); Engelmann and Grimm (2009); Porter and Vragov (2006)), researchers have attempted to identify factors that drive overbidding, such as the anticipation of regret, the joy of winning (Cooper and Fang (2008)),

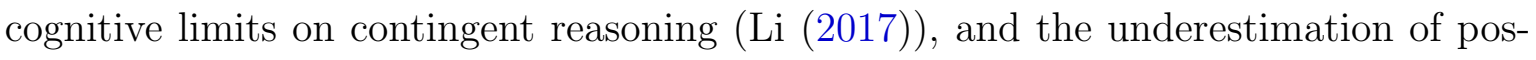
sible losses (Georganas et al. (2017)). Our results suggest that one of the key drivers of overbidding is the subjects' failure to grasp the strategy-proofness property of the Vickrey auction, even for those who perfectly understand the rule of the Vickrey auction.

Note that our statement of advice is quite simple, so that the same advice can be used in the two auctions. We emphasize that even such a piece of simple advice has a considerable net advice effect in the Vickrey auction. More detailed advice would

\footnotetext{
${ }^{25}$ According to the rule of the Ausubel auction, winners' demand reductions are censored in the Ausubel auction. For this reason, and for a fair comparison, we focus on non-winning bids in the Vickrey treatments.
} 
make the subjects bid more sincerely.

Our results show that a simple advice improves efficiency in the Vickrey auction, and this improvement is higher in early periods, when subjects are less experienced. Thus, our results show that advice improves efficiency in the Vickrey auction by promoting a better understanding of the strategy-proofness property of the Vickrey auction.

To focus on the advice effect on bidding behavior, we conducted experiments in a "symmetric" environment, that is, an environment in which each bidder in the same auction has the same distribution function of valuations. As discussed in Section 3.4, the pay-your-bid auction as well as the Vickrey auction generated almost perfectly efficient outcomes in such a symmetric environment. Thus, even without advice, there is little room to improve efficiency in both auctions. That is, in our experiment, the effects of advice on efficiency are limited in both auctions. We conjecture that experiments in an "asymmetric" environment would clarify the advice effect on efficiency. 


\section{A Appendix: Binary efficiency}

Table 9 summarizes the frequencies of realization of efficient allocation by treatment. In what follows, we apply normal approximation as we do in Section 3.2. Suppose the achievement of efficient allocation in treatment $j \in\{\mathrm{VA}, \mathrm{VN}, \mathrm{PA}, \mathrm{PN}\}$ is a realization of a random variable $E_{j}$ with a Bernoulli distribution that takes 1 (= efficient) with a success rate of $q_{j}$. That is,

$$
E_{j} \equiv \begin{cases}1 & \text { with prob. } q_{j}, \\ 0 & \text { with prob. } 1-q_{j} .\end{cases}
$$

Let $\bar{E}_{j}$ denote the sample mean for $n_{j}^{\prime}$ realizations of $E_{j}$ and let

$$
\Gamma_{j} \equiv \frac{\bar{E}_{j}\left(1-\bar{E}_{j}\right)}{n_{j}^{\prime}}
$$

\begin{tabular}{|c|c|c|c|c|c|c|c|c|}
\hline \multirow{2}{*}{\multicolumn{2}{|c|}{ Data }} & \multicolumn{2}{|c|}{ Vickrey } & \multirow{2}{*}{$\begin{array}{c}(1) \\
\mathrm{VA}-\mathrm{VN}\end{array}$} & \multicolumn{2}{|c|}{ Pay-your-bid } & \multirow{2}{*}{$\begin{array}{c}(2) \\
\text { PA-PN }\end{array}$} & \multirow[b]{2}{*}{$(1)-(2)$} \\
\hline & & VA & VN & & PA & PN & & \\
\hline All periods & $\begin{array}{l}\bar{e}_{j}^{a p} \\
\gamma_{j}^{a p}\end{array}$ & $\begin{array}{c}0.779 \\
\left(3.28 \times 10^{-4}\right)\end{array}$ & $\begin{array}{c}0.705 \\
\left(5.20 \times 10^{-4}\right)\end{array}$ & $0.074^{* * *}$ & $\begin{array}{c}0.823 \\
\left(2.54 \times 10^{-4}\right)\end{array}$ & $\begin{array}{c}0.783 \\
\left(2.83 \times 10^{-4}\right)\end{array}$ & $0.039^{* *}$ & $0.035^{* *}$ \\
\hline Periods 1-13 & $\begin{array}{l}\bar{e}_{j}^{f p} \\
\gamma_{j}^{f p}\end{array}$ & $\begin{array}{c}0.744 \\
\left(6.98 \times 10^{-4}\right) \\
\end{array}$ & $\begin{array}{c}0.644 \\
\left(1.10 \times 10^{-3}\right)\end{array}$ & $0.099^{* * *}$ & $\begin{array}{c}0.823 \\
\left(4.88 \times 10^{-4}\right)\end{array}$ & $\begin{array}{c}0.782 \\
\left(5.46 \times 10^{-4}\right)\end{array}$ & $0.041^{*}$ & $0.059^{* *}$ \\
\hline Periods $14-25$ & $\begin{array}{l}\bar{e}_{j}^{l p} \\
\gamma_{j}^{l p}\end{array}$ & $\begin{array}{c}0.817 \\
\left(5.92 \times 10^{-4}\right) \\
\end{array}$ & $\begin{array}{c}0.771 \\
\left(9.20 \times 10^{-4}\right)\end{array}$ & $0.047^{*}$ & $\begin{array}{c}0.822 \\
\left(5.29 \times 10^{-4}\right)\end{array}$ & $\begin{array}{c}0.785 \\
\left(5.87 \times 10^{-4}\right)\end{array}$ & $0.038^{*}$ & 0.009 \\
\hline
\end{tabular}

Table 9: Binary efficiency by treatments and periods.

Notes: ${ }^{*}$ denotes significant at the $10 \%$ level, ${ }^{* *}$ at the $5 \%$ level, and ${ }^{* * *}$ at the $1 \%$ level. 


\section{References}

Abdulkadiroğlu, A. and T. Sönmez (2003) "School choice: A mechanism design approach," American Economic Review, 93, 729-747.

Angrist, J. D. and J. S. Pischke (2008) Mostly Harmless Econometrics: An Empiricist's Companion, Princeton University Press.

Attiyeh, G., R. Franciosi, and R. M. Isaac (2000) "Experiments with the pivotal process for providing public goods," Public Choice, 102, 95-114.

Ausubel, L. (2004) "An efficient ascending-bid auction for multiple objects," American Economic Review, 94, 1452-1475.

Brenner, M., D. Galai, and O. Sade (2009) "Sovereign debt auctions: Uniform or discriminatory?" Journal of Monetary Economics, 56, 267-274.

Cason, T., T. Saijo, T. Sjöström, and T. Yamato (2006) "Secure implementation experiments: Do strategy-proof mechanisms really work?" Games and Economic Behavior, 57, 206-235.

Chen, Y. and T. Sönmez (2006) "School choice: An experimental study," Journal of Economic Theory, 127, 202-231.

Cooper, D. J. and H. Fang (2008) "Understanding overbidding in second price auctions: An experimental study," Economic Journal, 118, 1572-1595.

Ding, T. and A. Schotter (2017a) "Matching and chatting: An experimental study of the impact of network communication on school-matching mechanisms," Games and Economic Behavior, 103, 94-115.

Ding, T. and A. Schotter (2017b) "Learning and mechanism design: An experimental test of school matching mechanisms with intergenerational advice," mimeo.

Engelmann, D. and V. Grimm (2009) "Bidding behavior in multi-unit auctions: An experimental investigation and some theoretical insights," Economic Journal, 119, 855-882.

Fischbacher, U. (2007) "z-Tree: Zurich toolbox for readymade economic experiments," Experimental Economics, 10, 171-178. 
Garratt, R. J., M. Walker, and J. Wooders (2012) "Behavior in second-price auctions by highly experienced eBay buyers and sellers," Experimental Economics, 15, 44-57.

Georganas, S., D. Levin, and P. McGee (2017) "Optimistic irrationality and overbidding in private value auctions," Experimental Economics, 20, 772-792.

Grether, D. and C. Plott (1979) "Economic theory of choice and the preference reversal phenomenon," American Economic Review, 69, 623-638.

Guillen, P. and R. Hakimov (2017) "Not quite the best response: Truth-telling, strategy-proof matching, and the manipulation of others," Experimental Economics, 20(3), 670-686.

Guillen, P. and R. Hakimov (2018) "The effectiveness of top-down advice in strategyproof mechanisms: A field experiment," European Economic Review, 101, 505511.

Guillen, P. and A. Hing (2014) "Lying through their teeth: Third party advice and truth telling in a strategy proof mechanism," European Economic Review, 70, $178-185$.

Hanaki, N., N. Jacquemet, S. Luchini, and A. Zylbersztejn (2016) " Cognitive ability and the effect of strategic uncertainty," Theory and Decision, 81, 101-121.

Hassidim, A., D. Marciano, A. Romm, and R. I. Shorrer (2017) "The mechanism is truthful, why aren't you?" American Economic Review, 107, 220-224.

Harstad, R. M. (2000) "Dominant strategy adoption and bidders' experience with pricing rules," Experimental economics, 3, 261-280.

Holmström, B. (1979) "Groves' scheme on restricted domains," Econometrica, 47, $1137-1144$.

Jacquemet, N. and O. L'Haridon (2018) Experimental Economics: Method and Applications, Cambridge University Press.

Kagel, J. H. and D. Levin (1993) "Independent private value auctions: Bidder behaviour in first-, second- and third-price auctions with varying numbers of bidders," Economic Journal, 103, 868-879. 
Kagel, J. H. and D. Levin (2001) "Behavior in multi-unit demand auctions: Experiments with uniform price and dynamic Vickrey auctions," Econometrica, 69, $413-454$.

Kagel, J. H. and D. Levin (2009) "Implementing efficient multi-object auction institutions: An experimental study of the performance of boundedly rational agents," Games and Economic Behavior, 66, 221-237.

Kagel, J. H. and D. Levin (2016) "Auctions: A survey of experimental research," in Handbook of Experimental Economics, Vol. 2, (J. H. Kagel and A. E. Roth eds.), Princeton University Press.

Kawagoe, T. and T. Mori (2001) "Can the pivotal mechanism induce truth-telling? An experimental study," Public Choice, 108, 331-354.

Kwasnica, A. M. and K. Sherstyuk (2013) "Multiunit auctions," Journal of Economic Surveys, 27, 461-490.

Lebrun, B. and M.-C. Tremblay (2003) "Multiunit pay-your-bid auction with onedimensional multiunit demands," International Economic Review, 44, 1135-1172.

Li, S. (2017) "Obviously strategy-proof mechanisms," American Economic Review, 107, 3257-3287.

List, J. A. (2001) "Do explicit warnings eliminate the hypothetical bias in elicitation procedures? Evidence from field auctions for sportscards," American Economic Review, 91, 1498-1507.

Manelli, A. M., M. Sefton, and B. Wilner (2006) "Multi-unit auctions: A comparison of static and dynamic mechanisms," Journal of Economic Behavior and Organization, 61, 304-323.

Marszalec, D. (2017) "The impact of auction choice on revenue in treasury bill auctions - An empirical evaluation," International Journal of Industrial Organization, 53, 215-239.

Milgrom, P. (2000) "Putting auction theory to work: The simultaneous ascending auction," Journal of Political Economy, 108, 245-272.

Okamoto, N. (2018) "An efficient ascending-bid auction for multiple objects: Comment," American Economic Review, 108, 555-560. 
Porter, D. and R. Vragov (2006) "An experimental examination of demand reduction in multi-unit versions of the Uniform-price, Vickrey, and English auctions," Managerial and Decision Economics, 27, 445-458.

Roth, A. E., T. Sömez, and M. Ünver (2004) "Kidney exchange," Quarterly Journal of Economics, 119, 457-488.

Saijo, T., T. Sjöström, and T. Yamato (2007) "Secure implementation," Theoretical Economics, 2, 203-229.

Shogren, J. F., M. Margolis, C. Koo, and J. A. List (2001) "A random $n$ th-price auction," Journal of Economic Behavior and Organization, 46, 409-421.

Velez, R. A. and A. L. Brown (2020) "Empirical strategy-proofness," mimeo.

Vickrey, W. (1961) "Counterspeculation, auctions, and competitive sealed tenders," Journal of Finance, 16, 8-37.

Zizzo, D. J. (2009) "Experimenter demand effects in economic experiments," Experimental Economics, 13, 75-98. 